
Not for reproduction, distribution or commercial use.

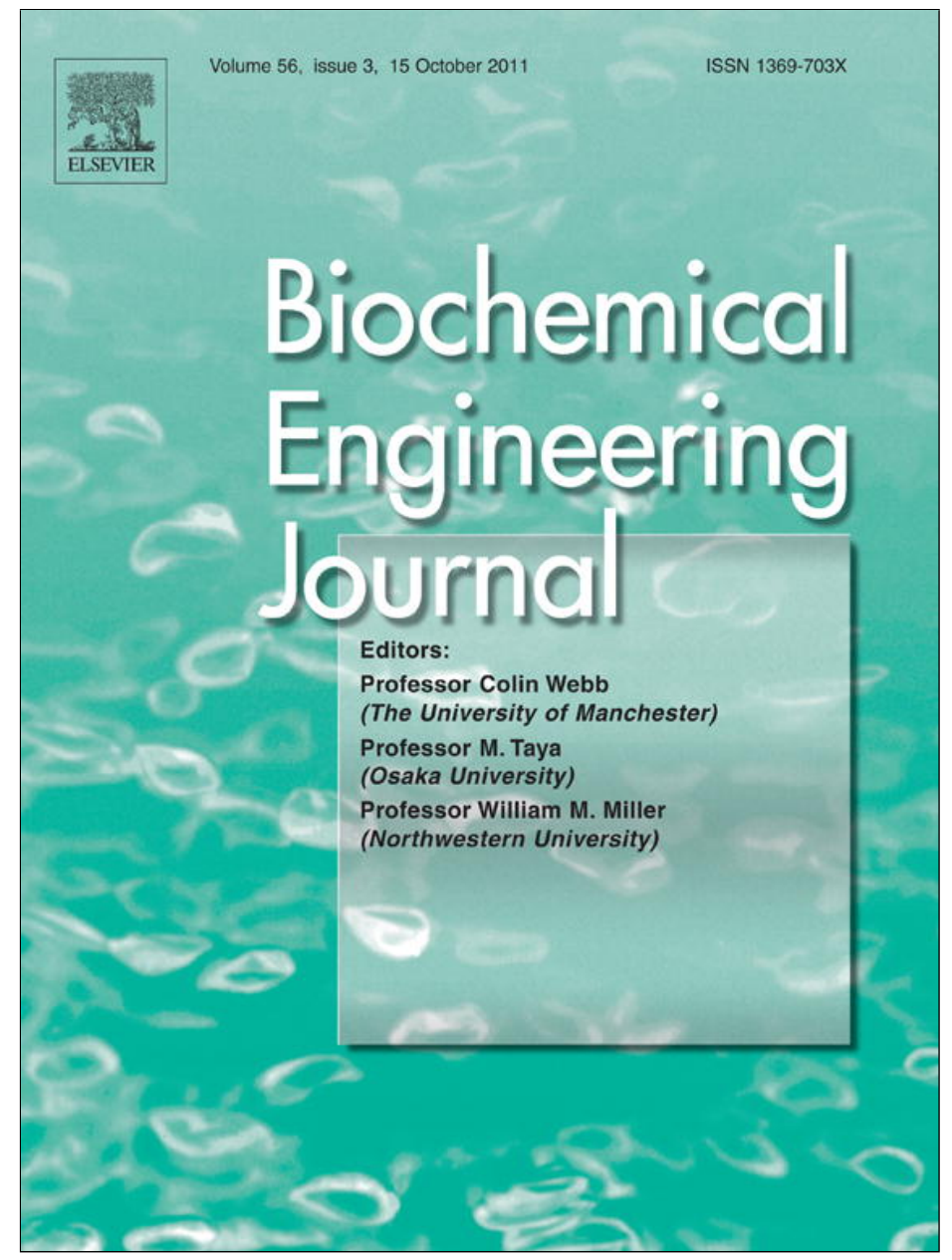

This article appeared in a journal published by Elsevier. The attached copy is furnished to the author for internal non-commercial research and education use, including for instruction at the authors institution and sharing with colleagues.

Other uses, including reproduction and distribution, or selling or licensing copies, or posting to personal, institutional or third party websites are prohibited.

In most cases authors are permitted to post their version of the article (e.g. in Word or Tex form) to their personal website or institutional repository. Authors requiring further information regarding Elsevier's archiving and manuscript policies are encouraged to visit:

http://www.elsevier.com/copyright 


\title{
Enzymatic synthesis of biodiesel from fatty acids. Kinetics of the reaction measured by fluorescent response of Nile Red
}

\author{
Sergey N. Fedosov*, Xuebing Xu \\ Dept. Molecular Biology, Aarhus University, Science Park, Gustav Wieds Vej 10C, 8000 Aarhus C, Denmark
}

\section{A R T I C L E I N F O}

\section{Article history:}

Received 21 March 2011

Received in revised form 13 June 2011

Accepted 17 June 2011

Available online 23 June 2011

\section{Keywords:}

Biodiesel

Fatty acids

Enzyme biocatalysis

Lipase

Kinetic parameters

Modeling

\begin{abstract}
A B S T R A C T
Production of biodiesel (B) from free fatty acids (F) was investigated. Different amounts of $F$ dissolved in B were esterified by methanol or ethanol with help of lipase Novozym 435. The kinetic model included (i) steady-state scheme; (ii) reversible inhibition of the enzyme by alcohols; and (iii) aggregation of water $\mathrm{W}+\mathrm{W} \leftrightarrow \mathrm{WW}$. The aggregated form $\mathrm{WW}$ imitated large water droplets with low chemical activity. Forward and backward reactions were recorded using the calibrated fluorescent signal from Nile Red. The relevant rate constants were calculated and used in computer simulations. The model demonstrated that content of $\mathrm{F}$ could be decreased below the specification level of $0.25 \%$ by means of the enzymatic conversion exclusively. It was found that the reaction could be accomplished in one step starting from content of $\mathrm{F} \leq 1 \%$, water $=100 \mathrm{ppm}$ and $\mathrm{MeOH}=6 \%$ or $\mathrm{EtOH}=13 \%$. The higher levels of $\mathrm{F}(\geq 4 \%)$ would require three cycles where $\mathrm{MeOH}(\geq 4 \%)$ or $\mathrm{EtOH}(\geq 7 \%)$ are added at the beginning of each step, and water is dried to $100 \mathrm{ppm}$ between the steps. The designed kinetic scheme is a part of the general biodiesel reaction model, which is currently under construction.
\end{abstract}

(C) 2011 Elsevier B.V. All rights reserved.

\section{Introduction}

Biodiesel (B) is a sustainable fuel produced in the reaction of (trans)esterification, where fatty acids (F) of vegetable oil are conjugated to an alcohol giving the corresponding esters [1-6]. The oil substrates of the reaction are: F, triglycerides (T), diglycerides (D) and monoglycerides (M). The alcohol of typical choice is either methanol $\left(\mathrm{MeOH}, \mathrm{C}_{1}\right)$ or ethanol $\left(\mathrm{EtOH}, \mathrm{C}_{2}\right)$, though long-chain alcohols are also considered [1-6]. The reaction requires a catalyst, where inorganic alkali are used most often [1-6].

Recently, application of the immobilized enzymes (e.g. lipase CALB, trademark Novozym 435) attracted much attention due to affordable prices $[1,3,4]$. Enzymatic transesterification has a number of advantages including (a) minimal industrial waste; (b) reusability; (c) low sensitivity to the composition of feedstock;

Abbreviations: $\mathrm{B}$, biodiesel; $\mathrm{B}_{1}$, methanol based $\mathrm{B}$; $\mathrm{B}_{2}$, ethanol based $\mathrm{B}$; CALB Candida antarctica lipase $\mathrm{B}$; $\mathrm{C}$, alcohol; $\mathrm{C}_{1}, \mathrm{MeOH}$, methanol; $\mathrm{C}_{2}$, EtOH, ethanol; $\mathrm{E}$, enzyme; EX, enzyme with attached fatty acid; FAEE, fatty acid ethyl ester; FAME, fatty acid methyl ester; $F$, fatty acid (free); $\mathrm{m} / \mathrm{m}$, mass per mass; $\mathrm{m} / \mathrm{v}$, mass per volume; $F R$, fluorescent ratio; OA, oleic acid; T/D/M, tri-/di-/mono-glyceride; TLCFID, thin layer chromatography assisted by flame ionization detector; $\mathrm{v} / \mathrm{v}$, volume per volume; $\mathrm{W}$, water.

* Corresponding author. Tel.: +45 894250 90; fax: +4586136597.

E-mail address: snf@mb.au.dk (S.N. Fedosov). and (d) high velocity of the reaction even at ambient temperatures and low alcohol concentrations $[1,3,4]$. Optimization of such process is, however, not an easy task. First of all, the reaction is reversible, and increasing concentrations of alcohol are required to shift the equilibrium toward the products (preferably compliant with the specifications for biodiesel [3]). Yet, excess of $\mathrm{MeOH}$ or EtOH causes both reversible inhibition and irreversible inactivation of lipases $[1,3,4]$. A good knowledge of the reaction kinetics and inhibition patterns is necessary to reach a high conversion degree preserving at the same time the enzymatic activity.

Kinetic analysis of the biodiesel reaction usually follows the two below strategies. The first one is an empiric approach, where the final yield is presented as a polynomial function of the reaction conditions $[7,8]$. Yet, reliability of such method is low because the polynomial function does not truly reflect any physical or chemical law and might significantly deviate from the true chart course. Another approach is based on the correct equations of enzyme kinetics $[9,10]$. This method is potentially much more perspective, but the conclusions are often compromised by a cumbersome experimental design. For example, description of the global scheme requires a very complex kinetic mechanism with at least $15-20$ parameters. Such model is usually applied to a limited number of experimental points (30-50), which severely reduces reliability of the calculated rate constants. 


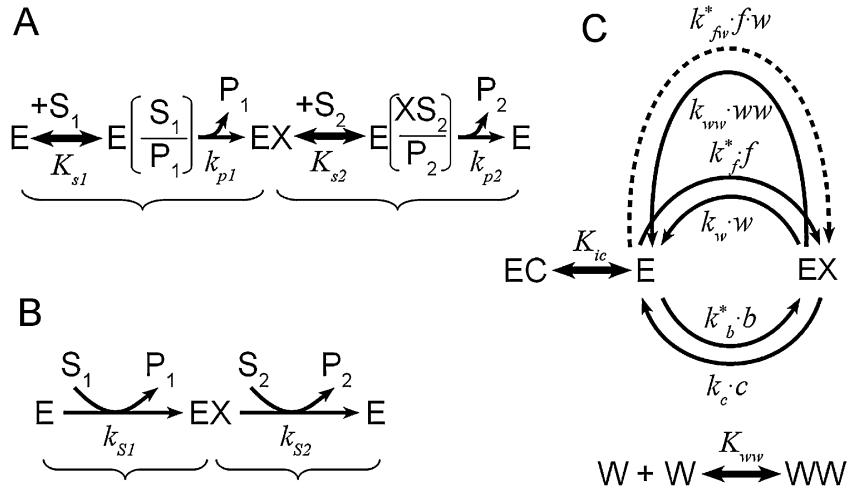

Fig. 1. Kinetic schemes. (A) Full scheme of the ping-pong mechanism, where concentrations of $\mathrm{P}_{1}$ and $\mathrm{P}_{2}$ are close to zero. (B) Shortened scheme of the ping-pong reaction. (C) The analyzed reaction scheme presented as a King-Altman master pattern. Notation is as follows: $\mathrm{B}$ - biodiesel (either $\mathrm{B}_{1}$ or $\mathrm{B}_{2}$ ), $\mathrm{C}-$ alcohol $\left(\mathrm{C}_{1}=\mathrm{CH}_{3} \mathrm{OH}, \mathrm{C}_{2}=\mathrm{C}_{2} \mathrm{H}_{5} \mathrm{OH}\right), \mathrm{E}$ - free enzyme, $\mathrm{EX}$ - the enzyme with attached fatty acid, $\mathrm{F}$ - fatty acid, $\mathrm{W}$ - finely dispersed water, WW - water layer. The rate coefficients labeled by stars are sensitive to enzyme inhibition, see the main text for further details.

The above reasoning emphasizes necessity to (i) simplify the kinetic scheme within the reasonable limits; (ii) reduce the number of reactants in the examined reactions; and (iii) collect as many points as possible. Several perspective approaches are sketched below and will be examined in the current publication.

Simplification of the kinetic scheme can be done as follows. Any elementary lipase reaction involves at least two substrates $\left(S_{1}, S_{2}\right.$, e.g. $F$ and $\left.C\right)$ and two products $\left(P_{1}, P_{2}\right.$, e.g. $B$ and $\mathrm{W})$. Such reaction follows the ping-pong mechanism (Fig. 1A) with four steps present $[9,10]$. Yet, the scheme can be condensed to two steps if assuming low affinity of the ligands for the enzyme (Fig. 1B). This is seemingly the case according to the available data on kinetics of the enzymatic biodiesel production [9]. The reduced scheme will be, therefore, explored as a fair approximation of the classical ping-pong mechanism.

Analysis of kinetics becomes much easier if working with partial reactions, where the number of ligands is confined to the absolute minimum. The most convenient system is esterification of free $\mathrm{F}$ in the presence of an alcohol $\mathrm{F}+\mathrm{C} \leftrightarrow \mathrm{B}+\mathrm{H}_{2} \mathrm{O}$ (all dissolved in biodiesel). This reaction is isolated from conversions of glycerides $\mathrm{M} \leftrightarrow \mathrm{D} \leftrightarrow \mathrm{T}$, and it can be described by relatively simple equations. Therefore, the reaction of esterification was chosen as a good starting point to construct the global model.

Enzymatic conversion of $\mathrm{F}$ to $\mathrm{B}$ presents a considerable interest for the industrial purposes. For example, many feedstocks have high initial content of $\mathrm{F}$, which makes these oils inapplicable for the direct alkaline esterification. Fatty acids are also major contaminants of biodiesel produced from a vegetable oil treated by aqueous EtOH in the presence of an enzyme [11]. Decrease of $F$ content below $0.25 \%$ (recalculated acid value of EN 14214 standard [3]) is difficult and requires detailed quantification of the reaction kinetics. This subject will be explored in the current publication.

Collection of numerous points is a prerequisite of any successful kinetic analysis. Yet, the well established methods of gas-chromatography, HPLC and TLC are relatively lengthy (discussed earlier [11]). In this publication we will examine application of the fluorescent probe Nile Red for monitoring of the reaction progress. Nile Red is soluble in organic liquids and changes its quantum yield in the presence of hydrophilic groups dissolved in the medium $[12,13]$. For example, organic alcohols (C) reversibly inter- act with Nile Red via hydrogen bonding and cause a noticeable red shift of its emission spectrum. Appearance or disappearance of those reactants can be recorded using emission of the fluorophore. The reaction of esterification $\mathrm{F}+\mathrm{C} \rightarrow \mathrm{B}+\mathrm{H}_{2} \mathrm{O}$ presents a very convenient example, where both substrates have hydrophilic groups and are active toward Nile Red. They disappear in course of reaction and produce two products - a hydrophobic molecule of B ("neutral" toward fluorophore) and water (excluded from the oil phase). A noticeable change of Nile Red emission can be expected. Correlation of the fluorescent signal with concentration of a reactant will facilitate monitoring of the reaction progress.

In the current publication we have analyzed kinetics of the enzymatic reaction $\mathrm{F}+\mathrm{C} \leftrightarrow \mathrm{B}+\mathrm{H}_{2} \mathrm{O}$ using the calibrated fluorescent response from Nile Red. The obtained data were used in design of a computer model, where reduction of $\mathrm{F}$ in "raw" biodiesel was simulated and optimized. This work describes the first stage in reconstruction of the full scheme of the enzymatic biodiesel production.

\section{Materials and methods}

\subsection{Materials}

All salts and solutions were purchased from Sigma-Aldrich. TLC-FID Chromarods S III were form SES GmbH - Analysesystem (Germany). TLC plates Polygram Sil G $20 \times 20 \mathrm{~cm}$ (gel $0.2 \mathrm{~mm}$ ) were from Macherey-Nagel (Germany). Preparation of $\mathrm{F}$ (oleic acid, 98\% purity) was purchased from Danisco (Denmark). Biodiesel of 96-97\% purity was prepared as described below using rapeseed oil from Danish supermarket. Immobilized lipase Novozym 435 was kindly provided by Novozymes (Denmark).

\subsection{Methods}

\subsubsection{Glossary of the model and molecular characteristics of the reactants}

A one letter code was adopted in the kinetic schemes and equations: $\mathrm{B}_{1}$ (biodiesel FAME), $\mathrm{B}_{2}$ (biodiesel FAEE), $\mathrm{C}_{1}\left(\mathrm{CH}_{3} \mathrm{OH}\right), \mathrm{C}_{2}$ $\left(\mathrm{C}_{2} \mathrm{H}_{5} \mathrm{OH}\right), \mathrm{E}$ (the immobilized enzyme CALB, trademark Novozym 435), EX (the enzyme with conjugated fatty acid), $F$ (free fatty acid), W (water as a fine micella), WW (water as a large droplet or layer), $\sum \mathrm{W}$ (total water, $\mathrm{W}+2 \cdot \mathrm{WW}$ ). The molar concentrations (M) of the corresponding compounds were indicated as small letters, e.g. $b_{1}=\left[\mathrm{B}_{1}\right]$ etc. The notation of rate constants followed the above one-letter code, see Fig. $1 \mathrm{C}$. The calculations were based on the following assumptions of the molecular mass and density (g/mol, g/mL, respectively): $B_{1}(296,0.88), B_{2}(310,0.88), C_{1}(32$, $0.79), C_{2}(46,0.79), F(282,0.90), W(18,1.0)$. Pure solutions were assumed to have the below molarity (mol/L): $B_{1}(3.0), B_{2}(2.84), C_{1}$ (24.7), $C_{2}$ (17.2), F (3.2), W (55.5). The biodiesel solutions used in the experiments were of $\approx 96 \%$ purity, i.e. $2.85 \mathrm{M} \mathrm{B}_{1}$ and $2.72 \mathrm{M}$ $B_{2}$. Most reactions were performed in the presence of $4 \%(\mathrm{~m} / \mathrm{v})$ Novozym 435 at $30^{\circ} \mathrm{C}$ and $200 \mathrm{rpm}$, where molar concentration of the enzyme CALB was estimated as $100 \mu \mathrm{M}$ based on the information provided by manufacturers $\left(\approx 85 \mathrm{mg}\right.$ of CALB with $M_{\mathrm{w}} \approx 34,000$ bound per $1 \mathrm{~g}$ of the carrier). Other conditions are specified in the text.

\subsubsection{Preparation of biodiesel solutions}

Biodiesel preparations (both $\mathrm{B}_{1}$ and $\mathrm{B}_{2}$ ) were produced from rapeseed oil using a uniform method with Novozyme 435 (5\%, $\mathrm{m} / \mathrm{v}, 37^{\circ} \mathrm{C}, 200 \mathrm{rpm}$ in shake-flasks). Alcohol (either MeOH or dry EtOH) was added at zero time (1/3 equivalent of full conversion, i.e. $1 \mathrm{~mol}$ of alcohol per $1 \mathrm{~mol}$ of $\mathrm{T})$, after $24 \mathrm{~h}$ of incubation $(1 / 3$ 
equivalent) and after $48 \mathrm{~h}$ ( $1 / 2$ equivalent). After the overall incubation time of $72 \mathrm{~h}$, the mixture was taken out of the incubator, and glycerol was allowed to settle as a separate layer under the enzyme particles $(3 \mathrm{~h})$. Glycerol was removed by aspiration, 1/3 equivalent of alcohol was added, and the reaction was continued overnight. The liquid product was separated form the enzyme and centrifuged, whereupon excessive alcohol was evaporated by incubation in open shake-flasks $\left(37^{\circ} \mathrm{C}, 200 \mathrm{rpm}\right.$, overnight). Some amount of glycerol was additionally adsorbed on glass walls of the shake flask. The typical composition of the final product was as follows $(\%, \mathrm{~m} / \mathrm{m})$ : $\mathrm{B}=96 \%, \mathrm{~T} \approx 0.6 \%, \mathrm{D} \approx 1.1 \%, \mathrm{M} \approx 1.5 \%, \mathrm{~F} \approx 0.8 \%$ based on TLC or TLC-FID measurements [11]. The endogenous water was evaluated as $500-800$ ppm according to Karl Fisher titration.

\subsubsection{Reaction of $B$ with water}

Hydrolysis of $B$ (either $B_{1}$ or $B_{2}$ ) to free fatty acid and alcohol was conducted under the below conditions. A mixture of biodiesel and water $(14 \mathrm{~mL}$ in total) was placed into a standard $15 \mathrm{~mL}$ tube and pre-warmed to $30^{\circ} \mathrm{C}$ (approximately $30 \mathrm{~min}$ ). Before the reaction was started, the mixture was vigorously shaken, and a sample of $0.6 \mathrm{~mL}$ was collected. Then $560 \mathrm{mg}$ of the enzyme beads (Novozym $435,4 \%, \mathrm{~m} / \mathrm{v}$ ) were added, and the reaction was continued over $1 \mathrm{~h}$ $\left(30^{\circ} \mathrm{C}\right.$ and $\left.200 \mathrm{rpm}\right)$. The reaction tubes were placed horizontally in the shaking incubator to improve the mixing. At time intervals, the tubes were vigorously shaken, the enzyme particles were allowed to settle for $10-15 \mathrm{~s}$, whereupon the samples of $0.6 \mathrm{~mL}$ were collected from the top. They were kept in closed $0.6 \mathrm{~mL}$ vials to prevent evaporation of alcohol. The time of collection was compensated for the increasing enzyme concentration, see Section 2.2.5.

\subsubsection{Reaction of $F$ with alcohol}

Conversion of $\mathrm{F}$ to $\mathrm{B}$ in the presence of alcohol ( $\mathrm{MeOH}$ or EtOH) was conducted as described in previous paragraph. In short, the mixture of either $\mathrm{F}$ (oleic acid) + B + alcohol or pure $\mathrm{F}+$ alcohol was incubated with Novozyme 435 particles. The samples of oil phase (without the enzyme beads) were collected at time intervals and subjected to analysis as described below.

\subsubsection{Time correction}

The volume of the reaction mixture gradually decreased because of the sample collection. This caused the proportional increase of the enzyme concentration $(e)$ in the mixture. In order to use the constant $e$ throughout the whole experiment, the original time of collection was corrected assuming a direct proportionality of the accumulate product $(d p)$ to both the enzyme $(e)$ and the time interval $(d t)$, e.g. $d p=k_{s} \cdot s \cdot e \cdot d t$. Each time interval $d t$ was corrected as follows: $d t_{\text {corr }}=d t \cdot V_{0} / V_{\mathrm{X}}$, where $V_{0}$ and $V_{\mathrm{X}}$ represent the volumes of reaction mixture at zero time and after collection of the corresponding sample.

\subsubsection{Analysis of the collected samples}

The fluorescent response and composition of the collected samples were analyzed in the following way. The fluorescent probe Nile Red $(2.5 \mu \mathrm{L}$ of $140 \mu \mathrm{M}$ solution in dimethylformamide) was added to $0.6 \mathrm{~mL}$ of the reaction sample (final concentration of $0.58 \mu \mathrm{M}$ ). The mixture was vigorously shaken and centrifuged to precipitate the water phase ( $2 \mathrm{~min}, 5000 \mathrm{rpm})$. The upper oil phase $(0.5 \mathrm{~mL})$ was collected and placed into a disposable plastic cuvette for fluorescent measurements. After measurement of fluorescence (Section 2.2.7), the composition of several selected samples was analyzed by either TLC on plates or/and TLC-FID as described earlier [11]. Depending on the reaction conditions, the change of either $\mathrm{F}$ or $\mathrm{B}$ was followed over the time and correlated with the fluorescent signal.
Table 1

The elementary steps and constants of the model (Fig. 1C).

\begin{tabular}{lll}
\hline Reaction & Forward $k, \mathrm{M}^{-1} \mathrm{~min}^{-1}$ & Backward $k, \mathrm{M}^{-1} \mathrm{~min}^{-1}$ \\
\hline $\mathrm{F}+\mathrm{E} \leftrightarrow \mathrm{W}+\mathrm{EX}$ & $k_{f}=1500$ & $k_{w}=2600$ \\
$\mathrm{C}_{1}+\mathrm{EX} \leftrightarrow \mathrm{B}_{1}+\mathrm{E}$ & $k_{c 1}=2000$ & $k_{b 1}=180$ \\
$\mathrm{C}_{2}+\mathrm{EX} \leftrightarrow \mathrm{B}_{2}+\mathrm{E}$ & $k_{c 2}=1200$ & $k_{b 2}=150$ \\
$\mathrm{~F}+\mathrm{W}+\mathrm{E} \leftrightarrow \mathrm{WW}+\mathrm{EX}\left(\mathrm{C}_{1}\right)$ & $k_{f w}=10$ or $\leq 50$ & $k_{w w 1}=490$ \\
$\mathrm{~F}+\mathrm{W}+\mathrm{E} \leftrightarrow \mathrm{WW}+\mathrm{EX}\left(\mathrm{C}_{2}\right)$ & $k_{f w}=10$ or $\leq 50$ & $k_{w w 2}=80$ \\
$\mathrm{E}+\mathrm{C}_{1} \leftrightarrow \mathrm{EC}_{1}$ & $k_{+i c 1}=100^{\mathrm{a}}$ & $k_{-i c 1}=140^{\mathrm{a}} K_{i c 1}=1.4 \mathrm{M}$ \\
$\mathrm{E}+\mathrm{C}_{2} \leftrightarrow \mathrm{EC}_{2}$ & $k_{+i c 2}=100^{\mathrm{a}}$ & $k_{-i c 2}=40^{\mathrm{a}} K_{i c 1}=0.40 \mathrm{M}$ \\
$\mathrm{W}+\mathrm{W} \leftrightarrow \mathrm{WW}\left(\right.$ for $\left.\mathrm{C}_{1}\right)$ & $k_{+w 1}=100^{\mathrm{a}}$ & $k_{-w 1}=17^{\mathrm{a}} K_{w w 1}=0.17 \mathrm{M}$ \\
$\mathrm{W}+\mathrm{W} \leftrightarrow \mathrm{WW}$ (for $\left.\mathrm{C}_{2}\right)$ & $k_{+w 2}=100^{\mathrm{a}}$ & $k_{-w 2}=31^{\mathrm{a}} K_{w w 2}=0.31 \mathrm{M}$ \\
\hline
\end{tabular}

a The rate constants were deduced from the corresponding equilibrium dissociation constants. The value of the binding rate constants $k_{+}$was assigned to guarantee a near-equilibrium state of this process at any moment of the reaction.

\subsubsection{Measurement of the fluorescent signal}

A stock solution of Nile Red was prepared and diluted with dimethylformamide to approximately $140-150 \mu \mathrm{M}$. The concentration was evaluated by absorbance of Nile Red in methanol on Varian Cary 50 spectrophotometer (coefficient of molar absorbance $\left.\varepsilon_{552}=45,000 \mathrm{M}^{-1} \mathrm{~cm}^{-1}[12]\right)$. Nile Red solution was added to the reaction sample $(0.58 \mu \mathrm{M}$ final concentration, Section 2.2.6) and the fluorescent signal was recorded on Varian Eclipse fluorometer using the below settings: excitation at $519 \mathrm{~nm}$ (slit $5 \mathrm{~nm}$ ); emission spectrum $550-700 \mathrm{~nm}$ (slit $5 \mathrm{~nm}$ ) or emission at $570 \mathrm{~nm}$ and $630 \mathrm{~nm}$; photomultiplier $580 \mathrm{~V}$, see Section 4 for further details.

\subsubsection{Nonlinear regression analysis}

The approximation of nonlinear curves was done by computer program KyPlot 5 (KyensLab Inc., Japan) using quasi-Newton method of least squares.

\subsubsection{Computer simulations}

The progress of a reaction over the time was simulated by computer program COPASI 4.5 [14] supplied with the reaction scheme, the initial concentrations of the reactants and the required rate constants, see Table 1 .

\section{Theory}

A typical lipase reaction follows the ping-pong mechanism (Fig. 1A). If the enzyme operates at a very low saturation level $\left(s_{1} \ll K_{m 1}, s_{2} \ll K_{m 2}\right)$, the "classical" velocity equation of the ping-pong scheme can be simplified, see Appendix (Eqs. (A1) and (A2)). Introduction of the correction coefficients extends the working range of the simplified equation to $0-40 \%$ of maximal velocity as discussed elsewhere [15]. The simplified scheme is shown in Fig. 1B, where each reaction step (braces in Fig. 1B) is interpreted as an efficient collision between the ligand and either $\mathrm{E}$ (free biocatalyst) or EX (a biocatalyst molecule with covalently attached fatty acid). Each rate constant of the simplified model (Fig. 1B) corresponds to the combination of constants in the full model (Fig. 1A), e.g. $k_{s 1} \approx k_{p 1} /\left(1.3 \cdot K_{s 1}\right)$.

The designed reaction scheme of esterification is presented in Fig. 1C as a King-Altman master pattern. One letter code was adopted, where e.g. $\mathrm{F}$ and $f$ corresponded to the molecule of $\mathrm{F}$ and its concentration, respectively (see also Section 2.2.1). Apart from the main reaction cycle, two additional equilibrium patterns were added. For example, association of micellar water (W) into large droplets or a layer (WW) was imitated by the binding scheme $\mathrm{W}+\mathrm{W} \leftrightarrow \mathrm{WW}$ (dissociation constant $K_{w w}$ ). Water remained partially active even as a layer due to reactions at its interface, and hydrolysis of biodiesel by WW was described by the scheme $\mathrm{B}+\mathrm{WW} \rightarrow \mathrm{C}+\mathrm{F}+\mathrm{W}$ with the rate coefficient $k_{w w}$. An opposite reaction ("enzymatic synthesis" of WW with the rate constant $k_{f w}$ ) was also considered to avoid the thermodynamically awkward 

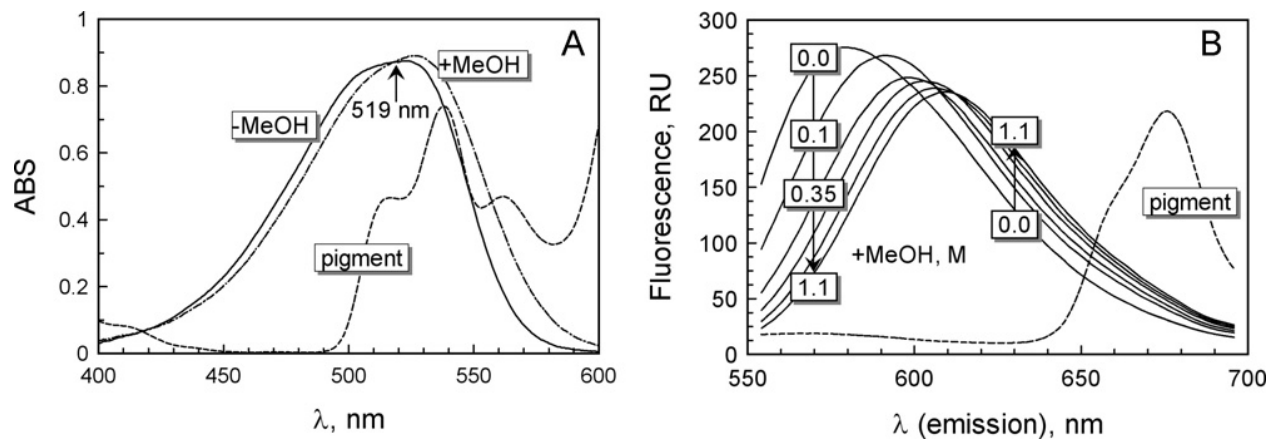

Fig. 2. Spectral properties of Nile Red. (A) Absorbance spectrum of Nile Red ( $18 \mu \mathrm{M}$ ) in biodiesel with or without $1 \mathrm{M} \mathrm{MeOH}$ ( $4 \%$, v/v), dash-dotted and solid lines, respectively. The excitation spectrum of discolored oil or biodiesel corresponded to zero line. The excitation spectrum (relative units) of endogenous pigments in raw oil or biodiesel (emission at $673 \mathrm{~nm}$ ) is shown by dashed line. (B) The emission spectra of Nile Red $(0.58 \mu \mathrm{M})$ in biodiesel with $0.0,0.1,0.35,0.6,0.85,1.1 \mathrm{M}$ of MeOH added, solid lines. The emission spectrum of biodiesel from discolored oil corresponded to zero line. The emission spectrum of biodiesel with endogenous pigments (excitation at 519 nm) is shown by dashed line.

assumption of irreversibility. Velocity of such conversion is obviously very low. The total concentration of water $\left(\sum w=w+2 \cdot w w\right)$ was expressed as its mass related to the total volume of the reaction mixture.

Distribution of alcohol $\mathrm{C}$ between oil and water phases was detected. Yet, formation of CW, CWW etc. complexes was ignored to prevent an extensive branching of the model. The alcohol concentration was treated as its total contents in the reaction volume disregarding phase distribution. At the same time, we assumed the effect of alcohols on formation $\left(K_{w w}\right)$ and chemical activity $\left(k_{w w}\right)$ of the aggregated water WW, containing $C$ as a "hidden" element. In such way, redistribution of alcohols between oil and water phases was "encoded" as properties of WW different in $\mathrm{MeOH}$ and EtOH related reactions. This subject will be additionally addressed in Sections 4.6 and 5.1.

The reversible inhibition of the enzyme by alcohol was considered as the unproductive binding $\mathrm{E}+\mathrm{C} \leftrightarrow \mathrm{EC}$ (dissociation constant $K_{i c}$ ). All reactions were performed under conditions, where no irreversible inactivation of the enzyme was detected, i.e. $\mathrm{MeOH} \leq 2 \mathrm{M}$ and $\mathrm{EtOH} \leq 3 \mathrm{M}$. A partial inactivation of Novozym 435 was found at $\mathrm{MeOH}$ and $\mathrm{EtOH} \geq 4 \mathrm{M}$ (not shown).

The velocity equation of the full scheme is presented in Appendix B.

\section{Results}

\subsection{Absorbance and fluorescence of Nile Red}

Absorbance spectra of Nile Red in $B_{1}$ (FAME) with or without $\mathrm{MeOH}(1 \mathrm{M}, 4 \%, \mathrm{v} / \mathrm{v})$ are shown in Fig. 2A. The absorbance remained constant at $519 \mathrm{~nm}$, which made this wavelength convenient for excitation of the probe. Biodiesel in all below experiments was produced from discolored oil, where the endogenous pigments were at a background level (not shown). Yet, raw oil was also tested. The performed test revealed presence of a fluorescing pigment, whose excitation spectrum (Fig. 2A, dashed line) partially overlapped the absorbance spectrum of Nile Red.

Emission spectra of Nile Red in $B_{1}$ with different amounts of $\mathrm{MeOH}$ are shown in Fig. 2B. As anticipated, they revealed high sensitivity of the probe to the presence of hydrophylic groups. The background fluorescence (or light scattering) of biodiesel from discolored oil was very low (not shown). The emission of pigments in raw oil (or biodiesel from raw oil) was, however, noticeable (Fig. 2B, dashed line). This makes the products from raw oil less suitable for fluorescent measurements, though, the pigment emission can be subtracted from the Nile Red emission spectrum. In the below kinetic experiments only discolored oil (or biodiesel) was used to avoid any ambiguity.

The fluorescent ratio $F R=F_{630} / F_{570}$ (i.e. the ratio of emission measured at $630 \mathrm{~nm}$ and $570 \mathrm{~nm}$ ) was chosen as a good indicator of Nile Red response to the changing composition of the medium. The ratio is independent of the amount of Nile Red, and all potential errors associated with dilution of the probe and varying turbidity of the samples can be ignored.

\subsection{Calibration of the fluorescent signal}

The fluorescent response was correlated with the concentration of chosen analyte (e.g. F) in the backward and forward reactions for both $\mathrm{MeOH}\left(\mathrm{C}_{1}\right)$ and $\mathrm{EtOH}\left(\mathrm{C}_{2}\right)$. For this purpose, the samples were collected during the reaction, whereupon they were analyzed in terms of both Nile Red fluoresce and the chemical composition [11]. The change of the fluorescent ratio was presented in absolute units $\triangle F R=\left|F R-F R_{0}\right|\left(F R=F_{630} / F_{570}\right)$, where $F R_{0}$ and $F R$ were measured before and under the reaction, respectively. The value of $\triangle F R$ was plotted versus the concentration changes (see Fig. 3 with calibrations).

All panels in Fig. 3 were analyzed similarly following the below logic. The experimental points were fitted by a suitable nonlinear function with two parameters (e.g. $\Delta F R=a \cdot(-\Delta f)^{n}$ in Fig. 3C). At the preliminary stage, an unconstrained fit was performed, and parameters of the best approximation were calculated. It appeared that one of the parameters fluctuated around an average value, whereas the other one was dependent on the initial concentrations of the reactants. After establishing this pattern, the fit was repeated, where the parameter without a clear tendency was fixed at its average value (e.g. $n=1.8$ in Fig. 3C) and the other one ( $a$ in Fig. 3C) was calculated again for each dataset. The obtained coefficients covered a broad range of the reaction conditions and connected the change of fluorescence $(\Delta F R)$ with the reactant (e.g. $-\Delta f=(\Delta F R / a)^{1 / 1.8}$, Fig. 3C). When the initial conditions differed from the described cases, the calibration coefficients were deduced by interpolation, see the functions for $a$ and $n$ coefficients in legend to Fig. 3 for further details. The discussed scheme of analysis was applied to all panels in Fig. 3, see below.

The calibration curves for the reactions $\mathrm{B}_{1}+\sum \mathrm{W} \rightarrow \ldots$ and $\mathrm{B}_{2}+\sum \mathrm{W} \rightarrow \ldots$ at different total water concentrations $\left(\sum w\right)$ are shown in Fig. $3 \mathrm{~A}$ and $\mathrm{B}$ (endogenous water was considered).

The calibration data for the reaction $\mathrm{F}+\mathrm{C}_{1} \rightarrow \ldots$ (Fig. 3C) were obtained in either biodiesel mixtures $\left(B_{1}\right.$ acting as a solventproduct) or pure $\mathrm{F}(f=3.2 \mathrm{M})$. Different initial combinations of $\mathrm{F}$, $\mathrm{B}_{1}$ and $\mathrm{MeOH}$ were used. One calibration curve approximated all 

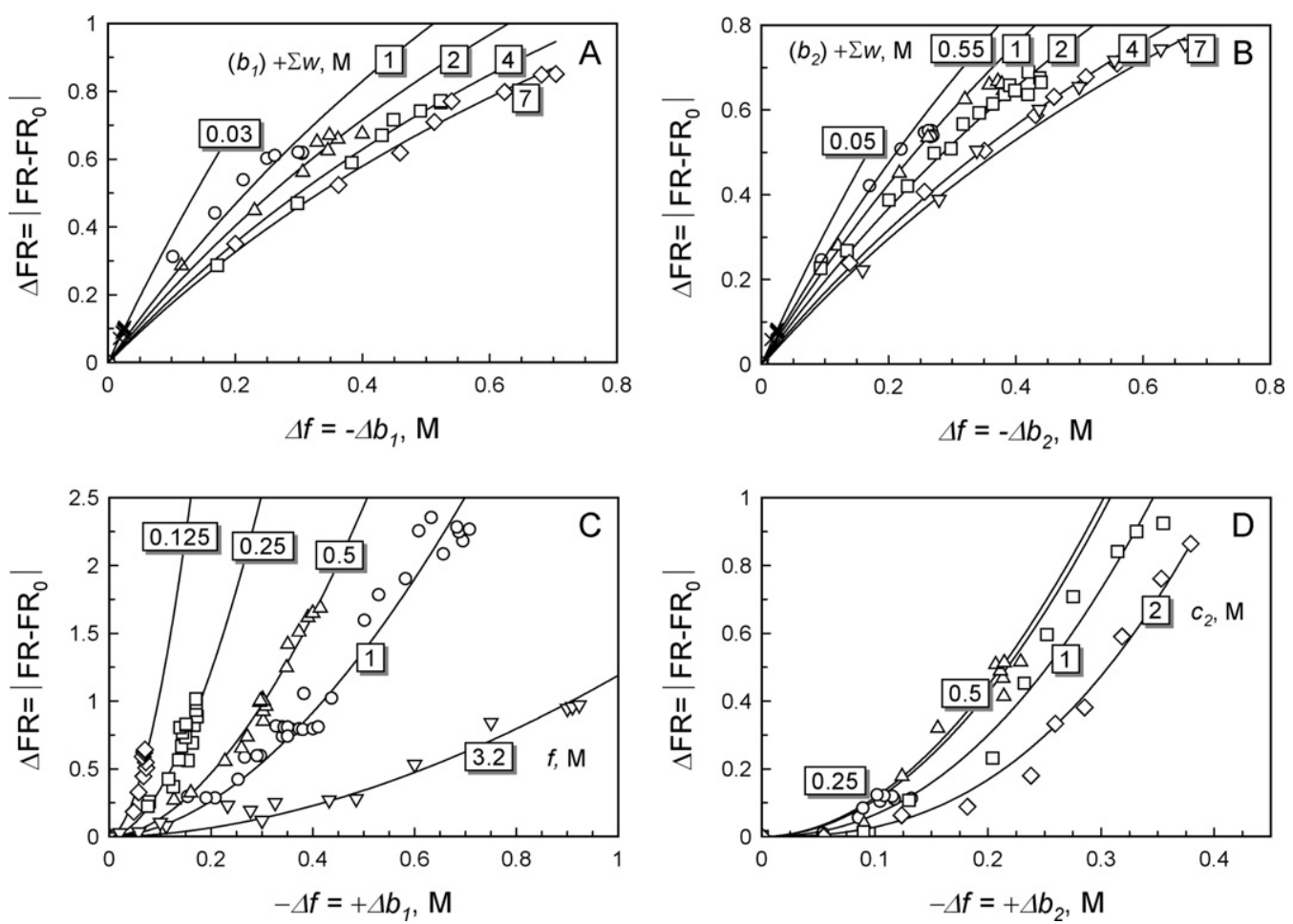

Fig. 3. Change of the fluorescent ratio $\triangle F R=\left|F R-F R_{0}\right|$ (absolute units) as a function of the concentration change. (A) Calibration curves for the reaction $\mathrm{B}_{1}+\sum \mathrm{W} \rightarrow \ldots$ at different initial water $\left(\sum w_{0}, \mathrm{M}\right), 0.03 \mathrm{M}$ corresponds to the endogenous water. The fitting equation was $\Delta F R=a /(1+1.4 / \Delta f)$ where coefficient $a$ depended on initial water $\sum w_{0}$ as $a=5.77-3.54 /\left(1+0.776 / \sum w_{0}\right)$. Change in $f$ was calculated as $\Delta f=1.4 /(a / \Delta F R-1)$. (B) Calibration curves for the $\mathrm{B}_{2}+\sum \mathrm{W} \rightarrow \ldots$ at different initial water $\left(\sum w_{0}, \mathrm{M}\right)$, $0.05 \mathrm{M}$ corresponds to endogenous water. The fitting equation and other calculations were as in panel A except for $a=4.80-2.77 /\left(1+0.99 / \sum w_{0}\right)$. (C) Calibration curves for the reaction $\mathrm{F}+\mathrm{C}_{1} \rightarrow \ldots$ in the mixtures of $\mathrm{F}, \mathrm{MeOH}$ and $\mathrm{B}_{1}$. Pure $\mathrm{F}$ corresponded to $3.2 \mathrm{M}$. The fitting equation was $\Delta F R=a \cdot(-\Delta f)^{1.8}$, where coefficient $a$ depended on the initial $\mathrm{F}$ concentration $f_{0}$ as $\log _{10}(a)=3.01-0.271 \cdot x-2.07 \cdot e^{-5.44 \cdot f o}$. Change in $\mathrm{F}$ was calculated as $-\Delta f=(\Delta F R / a)^{1 / 1.8}$. (D) Calibration curves for the reaction $\mathrm{F}+\mathrm{C}_{2} \rightarrow \ldots$ in the mixtures of $\mathrm{F}(0.52 \mathrm{M})$, EtOH and $\mathrm{B}_{2}$. The fitting equation was $\Delta F R=10.3 \cdot(-\Delta f)^{n}$, where coefficient $n$ depended on the initial EtOH concentration $c_{0}$ as $n=1.95+0.711 /\left(1+\left(2.37 / c_{0}\right)^{3.5}\right)$. Change in $\mathrm{F}$ was calculated as $-\Delta f=(\Delta F R / 10.3)^{1 / n}$.

reactions with the same initial $\mathrm{F}$ disregarding $\mathrm{MeOH}$ (see legend to Fig. 3C), at least within the tested limits of $0.5-1 \mathrm{M} \mathrm{MeOH}$ and $0.125 \mathrm{M}-3.2 \mathrm{M} \mathrm{F}$.

The calibration curves for the reaction and $\mathrm{F}+\mathrm{C}_{2} \rightarrow \ldots$ (Fig. 3D) covered a narrower span of conditions $(0.52 \mathrm{M}$ of initial $\mathrm{F}$ at different concentrations of EtOH). The fitting equations were used to calculate the change in $\mathrm{F}$ (legend to Fig. 3D). Fluorescent signal under the EtOH reaction with pure $\mathrm{F}(3.2 \mathrm{M})$ was ambiguous, because no reliable change of fluorescence was detected at the initial stage of the reaction (not shown).

In the mixtures $\mathrm{F}+\mathrm{B}$, purity of the added oleic acid (98\%) and presence of endogenous $F$ in biodiesel $\left(0.025 \mathrm{M}\right.$ in $B_{1}, 0.03 \mathrm{M}$ in $\left.\mathrm{B}_{2}\right)$ were considered when calculating $f$.

Coefficients of determination $R^{2}$ for the produced calibration curves (Fig. 3) varied in the range of $0.86-0.99$ (mean value of 0.97). Residual standard error of the fluorescent measurements was lower than that of TLC data by factor 1.7 , when both variables were plotted versus time (not shown). Therefore, the detailed analysis of the time curves was based mainly on the fluorescent records except for the cases with $\Delta F R \approx 0$, where TLC data were used instead.

The fluorescence of Nile Red in the artificial mixtures of substrates and products was tested and compared to the corresponding reaction samples. A deviation between the two datasets was found (not shown). It was probably caused by adsorption of some reactants on the surface of the enzyme particles leading to different composition of the oil phase in the artificial mixtures and the true reaction samples. This means that the substrate-product mixtures, though prepared at a correct proportion, are inapplicable for calibration of the reaction progress.

\subsection{Kinetic analysis of water-dependent hydrolysis of biodiesel (backward reaction)}

Different concentrations of water were added to biodiesel, whereupon Novozym 435 catalyzed hydrolysis of B to F and alcohol. Accumulation of free $\mathrm{F}$ was recorded using the fluorescent signal $\triangle F R$ and the calibration curves in Fig. $3 \mathrm{~A}$ and $\mathrm{B}$. The biodiesel preparations contained endogenous water assessed as $0.03 \mathrm{M}\left(\mathrm{B}_{1}\right)$ and $0.05 \mathrm{M}\left(\mathrm{B}_{2}\right)$.

The changes of $\Delta f$ over time (Fig. $4 \mathrm{~A}$ and $\mathrm{C}$ ) were fitted by exponential functions, whereupon the initial velocities (exponential slopes at zero time, $-v=+\Delta f \mid \Delta t=-\Delta b / \Delta t$ ) were calculated for each water concentration. Negative notation of $-v$ refers to the general expression of the reaction velocity $v=v_{\text {forward }}-v_{\text {backward }}$, see Appendix Eq. (B1). The velocities were used to produce dependencies of $-v / e_{0}$ versus total water $\sum w$ (endogenous water included). The reached equilibrium levels were also evaluated and used later under analysis of $K_{e q}^{a p p}$, see Section 4.7. The experiments with $\sum w=0.03 \mathrm{M}$ and $0.05 \mathrm{M}$ (Fig. 4A and C, respectively) corresponded to hydrolysis caused by endogenous water.

The relative velocities of backward reaction at zero time $\left(-v / e_{0}\right.$, $\min ^{-1}$ ) were plotted as functions of the total water (Fig. $4 \mathrm{~B}$ and D). It was assumed that only biodiesel and water were present in the appreciable amounts. This caused simplification of the general equation (Appendix B) to the below expression:

$-\frac{v}{e_{0}}=\frac{k_{b} \cdot b \cdot\left(k_{w} \cdot w+k_{w w} \cdot w w\right)}{k_{b} \cdot b+\left(k_{w} \cdot w+k_{w w} \cdot w w\right)} ; \quad w=F_{\left(\Sigma w, K_{w w}\right)} ;$

$w w=F_{\left(\Sigma w, K_{w w}\right)}$ 

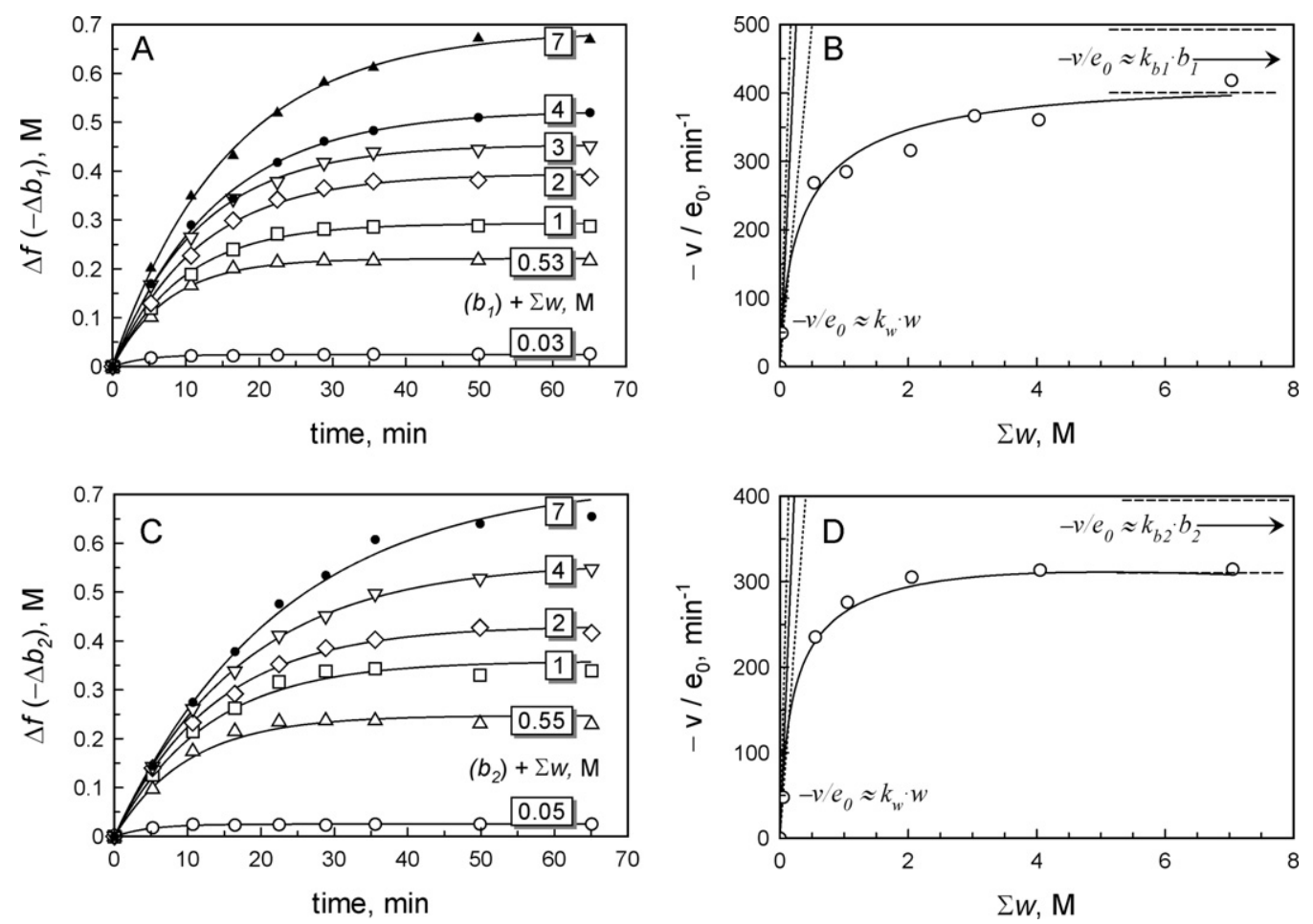

Fig. 4. Kinetics of biodiesel hydrolysis. (A) Accumulation of $F$ over time under hydrolysis of $B_{1}$ at different total water ( $0.03 \mathrm{M}$ corresponds to the endogenous water). (B) Velocity of $\mathrm{B}_{1}$ hydrolysis (reversible reaction with global velocity of $-v / e_{0}$ ) as a function of the total water concentration. Dashed and dotted lines indicate the boundaries of $k_{b 1} \cdot b_{1}$ and $k_{w} \cdot w$ evaluated under the preliminary analysis. The arrow shows the true level of $k_{b 1} \cdot b_{1}$. Solid line shows prediction of the final model (Table 1 ). (C) Accumulation of $\mathrm{F}$ over time under hydrolysis of $\mathrm{B}_{2}$ at different total water $\left(0.05 \mathrm{M}\right.$ corresponds to endogenous water). (D) Velocity of $\mathrm{B}_{2}$ hydrolysis $\left(-v / e_{0}\right)$ as a function of the total water concentration. Dashed and dotted lines indicate the boundaries of $k_{b 2} \cdot b_{2}$ and $k_{w} \cdot w$ evaluated under the preliminary analysis. The arrow shows the true level of $k_{b 2} \cdot b_{2}$. Solid line shows prediction of the final model (Table 1 ).

where $b$ stands for the biodiesel concentration (either $\mathrm{B}_{1}$ or $\mathrm{B}_{2}$ ), $w$ corresponds to the apparent concentration of micellar water, and $w w$ represents the aggregated water. Both $w$ and $w w$ are directly connected to the total concentration $\sum w$ via the equilibrium constant $K_{w w}$ and the binding equation (Appendix, Eqs. (C1) and (C2)). Initial concentration of biodiesel decreased with increasing water in accordance with the expressions: $b_{1}=2.85-0.0513 . \sum w$, and $b_{2}=2.72-0.049$. $\sum w$ (all in $\left.\mathrm{M}\right)$. The initial values of $2.85 \mathrm{M}$ and $2.72 \mathrm{M}$ corresponded to $\mathrm{B}_{1}$ and $\mathrm{B}_{2}$ of $96 \%$ purity.

The obtained velocity function (Eq. (1)) was too complex to make a reliable fit of the available data in Fig. 4C and D. Yet, it was possible to evaluate two rate constants, because Eq. (1) got simplified to $-v / e_{0} \approx k_{w} \cdot w$ at $\sum w \rightarrow 0\left(w \approx \sum w \gg w w\right)$ and $-v / e_{0} \approx k_{b} \cdot b$ at $\sum w \rightarrow \infty$. One can expect that the true value of $k_{b} \cdot b$ is situated above the experimental points, because dilution of biodiesel by water causes a downward deviation of the curve creating a plateau below its true level. The value of $k_{b 1}$ was estimated as $180 \mathrm{M}^{-1} \mathrm{~min}^{-1}$ (boundaries $160-200 \mathrm{M}^{-1} \mathrm{~min}^{-1}$ ), Fig. 4B. The value of $k_{b 2}$ was assessed as $150 \mathrm{M}^{-1} \mathrm{~min}^{-1}$ (boundaries $\left.130-160 \mathrm{M}^{-1} \mathrm{~min}^{-1}\right)$, Fig. 4D. The value of $k_{w}$ had probable boundaries of $1000-3000 \mathrm{M}^{-1} \mathrm{~min}^{-1}\left(k_{w} \approx 2000 \mathrm{M}^{-1} \mathrm{~min}^{-1}\right)$.

The solid lines in Fig. $4 \mathrm{~B}$ and $\mathrm{D}$ indicate predictions of the final model when all parameters of Eq. (1) were calculated (Table 1).

\subsection{Conversion of $F$ at different alcohol concentrations (forward reaction)}

In these experiments, a constant amount of $\mathrm{F}$ (mainly $\mathrm{OA}$ ) was reacted with different concentrations of alcohol (either $\mathrm{MeOH}$ or $\mathrm{EtOH}$ ) in the presence of Novozym 435. The preparations of $\mathrm{F}(\mathrm{OA})$ were either diluted with biodiesel $B_{1}$ and $B_{2}$ (containing $0.025 \mathrm{M}$ and $0.03 \mathrm{M}$ of endogenous $\mathrm{F}$, respectively) or used in the pure $\mathrm{OA}$.
The reaction progress was monitored by the fluorescent response transformed to the concentration of the consumed $\mathrm{F}$ (produced B) with help of the calibration charts in Fig. 3 C and D. Fluoresce data were equivocal when working with the mixtures of pure $\mathrm{F}$ and $\mathrm{MeOH}<0.3 \mathrm{M}$, or $\mathrm{EtOH}$ in the whole region of concentrations. Therefore, the corresponding reaction was analyzed by TLC. Examples of $\mathrm{F}$ utilization $(-\Delta f=+\Delta b$ over the time) are shown in Fig. $5 \mathrm{~A}$ (reaction of $1 \mathrm{M} \mathrm{F}$ with $\mathrm{MeOH}$ ) and Fig. $5 \mathrm{C}$ (reaction of $0.52 \mathrm{M} \mathrm{F}$ with $\mathrm{EtOH}$ ). The time curves were approximated by exponential functions, whereupon the slopes $-\Delta f / \Delta t$ were calculated at zero time (slope 0 ) as well as at $-\Delta f=0.2 \mathrm{M}$ for EtOH (slope 0.2 ), where $0.2 \mathrm{M}$ water was produced in course of reaction.

Dependencies of the normalized velocity $\left(v / e_{0}\right)$ on alcohol concentration $(c)$ are depicted in Fig. 5B (MeOH) and Fig. 5D (EtOH). It was assumed that only $\mathrm{F}, \mathrm{B}$ and $\mathrm{C}$ were present in the medium at the moment of the initial velocity measurements (slopes at $t_{0}$ ). Consequently, the general equation of the model in Appendix (B1) and (B2) was reduced to the below form:

$$
\frac{v}{e_{0}}=\frac{k_{f}^{*} \cdot f \cdot k_{c} \cdot c}{k_{b}^{*} \cdot b+k_{f}^{*} \cdot f+k_{c} \cdot c} ; \quad k_{x}^{*}=\frac{k_{x}}{1+c / K_{i c}}
$$

where reversible inhibition by alcohol was considered as expressions $k_{f}^{*}$ and $k_{b}^{*}$. The constant concentration of $\mathrm{F}(f=0.52 \mathrm{M}$, $1.02 \mathrm{M}$ in Fig. 5C and D, respectively) was maintained on the expense of biodiesel. The latter became dependent on alcohol as $b_{1}=1.95-0.11 \cdot c_{1}$ and $b_{2}=2.40-0.166 \cdot c_{2}$ (all in $\left.\mathrm{M}\right)$, mind different initial concentrations of $\mathrm{F}$ in these two cases. In the experiments with pure OA, $f$ decreased proportionally to the added alcohol in accordance with the expressions $f=3.2-0.04 \cdot c_{1}$ and $f=3.2-0.058 \cdot c_{2}(\mathrm{M})$.

A semi-quantitative graphical examination of Eq. (2) was undertaken. It was obvious that the initial slope at small $c$ 

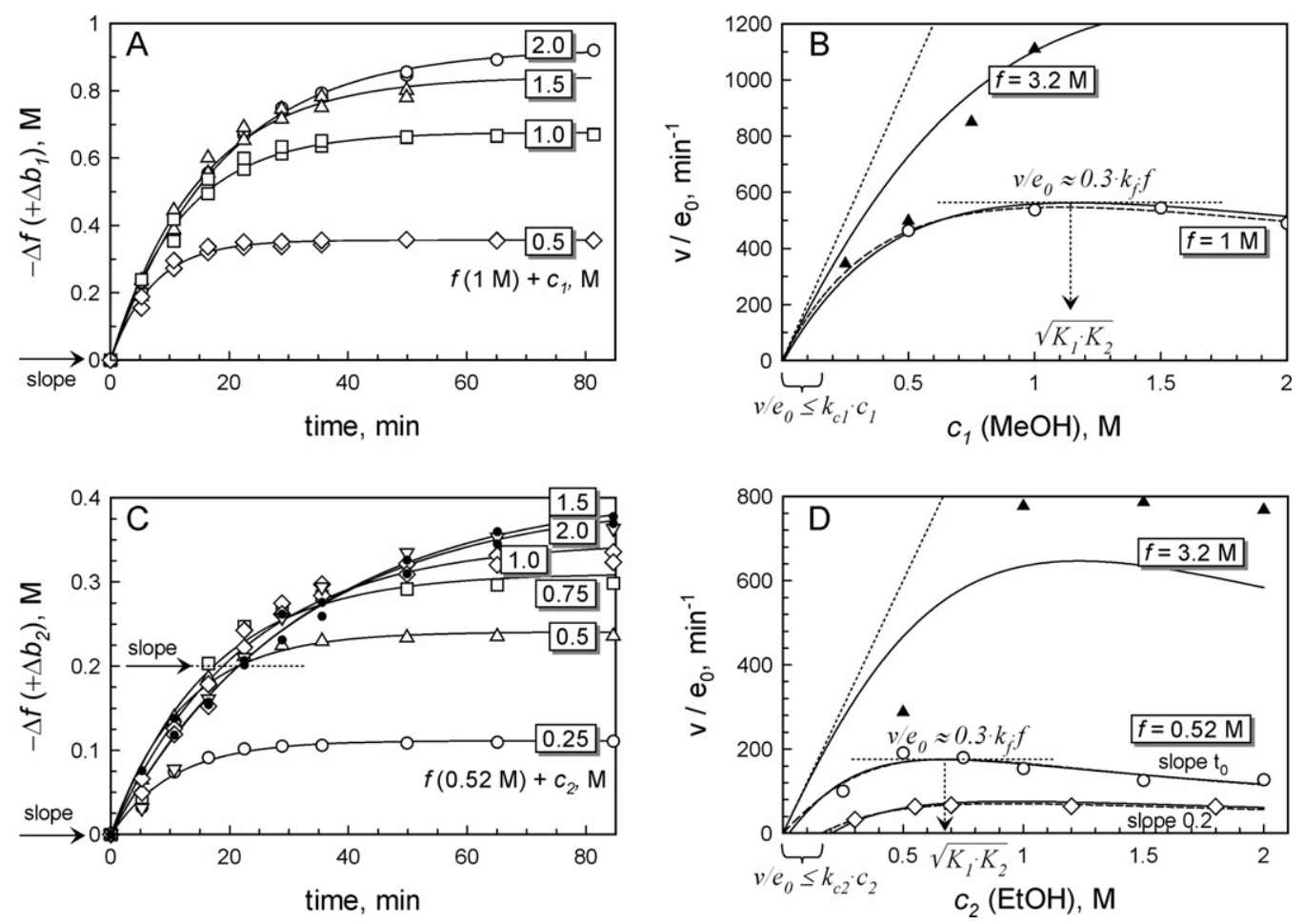

Fig. 5. Conversion of fatty acids in the presence of variable alcohol. (A) Time dependence of $\mathrm{F}$ utilization $\left(f_{0}=1.02 \mathrm{M}\right)$ at different MeOH concentrations $\left(c_{1}\right)$ dissolved in $\mathrm{B}_{1}$. (B) Initial velocity of $\mathrm{F}$ conversion $\left(v / e_{0}\right.$ at zero time) as a function of $\mathrm{MeOH}$ concentration. Dashed line $(\bigcirc)$ indicates the best fit $(\mathrm{Eq}$. $(2))$ for $\mathrm{F}+\mathrm{MeOH}$ in $\mathrm{B}_{1}$ with $k_{f}=1222$ $k_{c 1}=2296 \mathrm{M}^{-1} \mathrm{~min}^{-1}$; and $K_{i c}=1.77 \mathrm{M},\left(k_{b 1}=180\right.$ fixed). Results for pure F are shown as $(\boldsymbol{\Lambda})$. Solid lines describe behavior of the final model (Table 1$)$. (C) Time dependence of $\mathrm{F}$ utilization $\left(f_{0}=0.52 \mathrm{M}\right)$ at different EtOH concentrations $\left(c_{2}\right)$ dissolved in $\mathrm{B}_{2}$. (D) Velocity of $\mathrm{F}$ conversion as a function of EtOH concentration The values of $v / e_{0}$ correspond to zero time $(\bigcirc)$ and the intermediate step of reaction at $-\Delta f=0.2 \mathrm{M}(\diamond)$. Dashed line $(\bigcirc)$ indicates the best fit (Eq. (2)) for the reaction $\mathrm{F}+\mathrm{EtOH}$ in $\mathrm{B}_{2}$ with $k_{f}=2125$, $k_{c 2}=799 \mathrm{M}^{-1} \mathrm{~min}^{-1}$; and $K_{i c}=0.26 \mathrm{M},\left(k_{b 2}=150\right.$ fixed $)$. Velocities at the intermediate step $(\diamond)$ had the best fit coefficients of $k_{f}=993, k_{c 2}=1050, k_{w}^{a p p}=674 \mathrm{M}^{-1} \mathrm{~min}^{-1} ;$ and $K_{i c}=0.55 \mathrm{M},\left(k_{b 2}=150\right.$ fixed). Results for pure F are indicated as $(\mathbf{\Delta})$. Solid lines describe behavior of the system according to the final model (Table 1$)$.

$\left(v / e_{0} \approx c \cdot k_{c} /\left(1+\left(k_{b} \cdot b\right) /\left(k_{f} \cdot f\right)\right)\right)$ should be somewhat below $k_{c}$ depending on the balance between $f, b$ and their rate constants $\left(k_{b}\right.$ being relatively small). A rough evaluation pointed to the slope of $\approx 0.7 \cdot k_{c}$. More graphical information was obtained after transformation of Eq. (2) to Eq. (2A), where $b$ was assumed to be approximately constant:

$\frac{v}{e_{0}}=\frac{k_{f} \cdot f}{1+\left(K_{1} / c\right)+\left(c / K_{2}\right)} ; \quad K_{1}=\frac{k_{f} \cdot f+k_{b} \cdot b}{k_{c}} ; \quad K_{2}=K_{i c}$

Dependence of $v / e_{0}$ on $c$ has a maximum at $c=\sqrt{ } K_{1} \cdot K_{2}$. The values of $K_{1}$ and $K_{2}$ should be of comparable magnitude to get the observed shapes of the curves. In such case, the maximal velocity becomes equal to $v / e_{0} \approx 1 / 3 \cdot k_{f} \cdot f$. Difference in $K_{1}$ and $K_{2}$ does not affect this value very much, e.g. $v / e_{0}=0.5 \cdot k_{f} \cdot f$ at $K_{1} / K_{2}=1 / 4$ and $v / e_{0}=0.2 \cdot k_{f} \cdot f$ at $K_{1} / K_{2}=4$.

Graphical examination revealed the magnitudes of the relevant constants, whereupon the nonlinear regression analysis revealed parameters with higher precision. One of the rate constants in Eq. (2) was determined earlier during hydrolysis of biodiesel by water $\left(k_{b}\right)$. Therefore, only three parameters $\left(k_{f}, k_{c}\right.$, and $\left.K_{i c}\right)$ in Eq. (2) were subjected to optimization. The best fits are shown by dashed lines in Fig. 5B and D, and the optimal coefficients are presented in the figure legend. Later on, the optimal curves were substituted by the global model approximations, where the data from different experiments were considered. For example, the value of $k_{f}$ was expected to be identical in Fig. 5B (O), Fig. 5D $(\bigcirc)$ as well as in the following experiments, see Fig. 5D $(\diamond)$, Fig. 6C and D. The value of $k_{f} \approx 1500 \mathrm{M}^{-1} \mathrm{~min}^{-1}$ was satisfactory for all the mentioned datasets. Repeated fitting with fixed $k_{f}$ gave more accurate values of $k_{c}$, and $K_{i c}$ for each alcohol (Table 1). The simulations based on the final model are shown by solid lines (endogenous water and $\mathrm{F}$ were considered).
Another set of reaction velocities (Fig. 5D, $\diamond$ ) was calculated from the slopes at $-\Delta f=0.2 \mathrm{M}$ in Fig. $5 \mathrm{C}$. Such setup required introduction of water $(0.2+0.03 \mathrm{M})$ to the fitting equation:

$\frac{v}{e_{0}}=\frac{k_{f}^{*} \cdot f \cdot k_{c} \cdot c-k_{b}^{*} \cdot b \cdot k_{w}^{a p p} \cdot w_{x}}{k_{b}^{*} \cdot b+k_{f}^{*} \cdot f+k_{c} \cdot c+k_{w}^{a p p} \cdot w_{x}} ; \quad k_{x}^{*}=\frac{k_{x}}{1+c / K_{i c}}$

where all concentrations were adjusted on the value of consumed $F$, e.g. $f=f_{0}-0.2 ; b=b_{0}+0.2 \mathrm{M}$ etc. Water was interpreted as existing in the unknown form $\left(w_{x}\right)$ characterized by the apparent coefficient $k_{w}^{a p p}\left(k_{w}>k_{w}^{a p p}>k_{w w}\right)$. The rate constant $k_{f w}$ was ignored as being much less than all other coefficients. It should be noted that intersection with $x$-axis takes place not at zero but at $k_{f}$. $f \cdot k_{c} \cdot c=k_{b} \cdot b \cdot k_{w}^{a p p} \cdot w_{x}$. During the computer fitting (Fig. 5D, $\diamond$ ) $k_{f}$ was fixed at $1500 \mathrm{M}^{-1} \mathrm{~min}^{-1}$ as discussed in previous paragraph. The optimal fit is shown by dashed line over symbols $\diamond$ and the corresponding parameters are presented in the legend to Fig. 5C. The newly introduced water-related coefficient was equal to $k_{w}^{a p p}=675 \mathrm{M}^{-1} \mathrm{~min}^{-1}$, which agreed with the assumption of $k_{w}^{a p p}<k_{w} \approx 2000 \mathrm{M}^{-1} \mathrm{~min}^{-1}$ (Fig. 4B and D). Another constant $\left(k_{c 2}\right)$ was set to $1200 \mathrm{M}^{-1} \mathrm{~min}^{-1}$ based on all data in Fig. 5D. The simulations of the general model (Table 1 ) are shown by solid lines.

The reactions in pure $\mathrm{F}$ demonstrated high dispersion of points ( $\Delta$ in Fig. 5B and D), which made difficult an accurate interpretation. The general model (Table 1 ) provided satisfactory approximations (solid lines over $\mathbf{\Lambda}$ ), however.

\subsection{Conversion at varying $\mathrm{F}$ and constant $\mathrm{MeOH}$ (forward reaction)}

In this setup, the reaction scheme from previous section was examined in a different way. Variable amounts of $F$ were diluted 

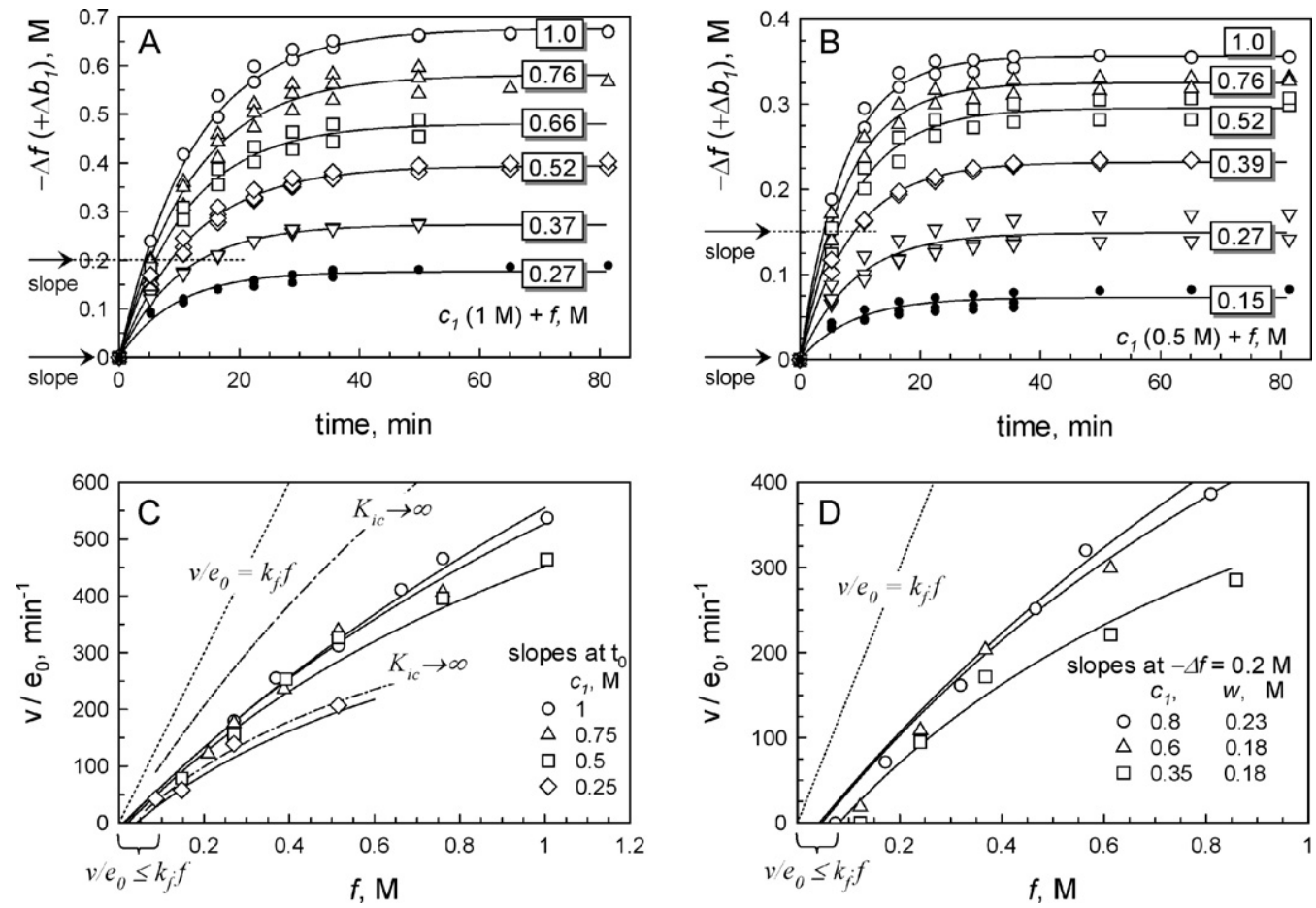

Fig. 6. Conversion of fatty acids (variable) in the presence of constant alcohol. Time dependencies of $\mathrm{F}$ utilization dissolved in $\mathrm{B}_{1}$ in the presence of $(\mathrm{A}) 1 \mathrm{M}$ MeOH $\left(c_{1}\right)$ and (B) $0.5 \mathrm{M} \mathrm{MeOH}\left(c_{1}\right)$. (C) Initial velocity of $\mathrm{F}$ conversion $\left(v / e_{0}\right.$ at zero time) as a function of $\mathrm{F}$ concentration. Solid lines describe behavior of the final model (Table 1 ). Dash-dotted lines demonstrate contradiction of fits if inhibition by MeOH is absent $\left(K_{i c} \rightarrow \infty\right)$. Dotted line shows the maximal slope at $f \rightarrow 0$. (D) Velocity of $\mathrm{F}$ conversion $\left(v / e_{0}\right.$ at $-\Delta f=0.2 \mathrm{M}$ ) as a function of $\mathrm{F}$ concentration. Solid lines describe behavior of the final model (Table 1 ). Dotted line shows the maximal slope at $f \rightarrow 0$.

with biodiesel $\left(\mathrm{B}_{1}\right)$ and exposed to the constant $\mathrm{MeOH}$ in four separate setups with initial $\mathrm{MeOH}=1,0.75,0.5,0.25 \mathrm{M}$. Changes in the $\mathrm{F}$ concentrations were recorded over time (examples for $1 \mathrm{M}$ and $0.5 \mathrm{M} \mathrm{MeOH}$ are presented in Fig. 6A and B, respectively). The slopes $-\Delta f / \Delta t$ were calculated at zero time in all four experiments and at the level of $-\Delta f=0.2,0.15$ and $0.15 \mathrm{M}$ for $\mathrm{MeOH}=1,0.75$ and $0.5 \mathrm{M}$, respectively. The obtained velocities $v / e_{0}$ were plotted as functions of F-concentration in Fig. 6C and D.

Analysis of $v / e_{0}$ versus $f$ employed Eqs. (2) and (3) from previous section, except for $f$ set now as a variable and $c$ set as a constant. Concentration of biodiesel became, therefore, connected to fatty acids via expressions $b_{1}=2.74-0.89 \cdot f\left(c_{1}=1 \mathrm{M}\right), b_{1}=2.79-0.89 \cdot f$ $\left(c_{1}=0.5 \mathrm{M}\right)$ etc. At a small $f$, the initial slope of the velocity function (Eq. (2)) was expected to be somewhat below $k_{f}$. A rough evaluation pointed to $v / e_{0} \approx 0.5 \cdot k_{f} \cdot f$. As discussed above, the value of $k_{f}$ should be identical in all experiments (Figs. 5B, D and 6C, D), and the value of $k_{f}=1500 \mathrm{M}^{-1} \mathrm{~min}^{-1}$ was assigned as discussed in Section 4.4. The alcohol inhibition ( $K_{i c} \approx 1.77 \mathrm{M}$ according to Fig. $\left.6 \mathrm{~B}\right)$ could not be determined in any of the separate fits in Fig. 6C, 6D because $c$ was constant for each curve. Therefore, the dissociation constant $K_{i c}$ was assigned in steps as $\infty$ (no inhibition), 5, 2, 1.5, $1 \mathrm{M}$. Then, the remaining rate constants $k_{c 1}$ (Fig. 6C and D) and $k_{w}^{a p p}$ (Fig. 6D) were subjected to optimization. If $K_{i c}$ was assigned correctly, all the curves will be described by similar values of $k_{c 1}$ and $k_{w}^{\text {app }}$. If not, the set of parameters optimal for one curve will be completely inconsistent with another one. The latter statement was evidently demonstrated for $K_{i c} \rightarrow \infty$ (Fig. 6C, dash-dotted lines), where a good fit for the dataset labeled as diamonds $\diamond$ provided a very poor fit for the dataset labeled as circles $\bigcirc$. After several trials, the value of $K_{i c}=1.4 \mathrm{M}$ was accepted as the best tradeoff between Figs. 5B and 6C, D.

Optimization of other parameters pointed to $k_{c 1}=1700-2100 \mathrm{M}^{-1} \mathrm{~min}^{-1}$ (Fig. 6C and D, Eq. (2)) and $k_{w}^{a p p}=700-1200 \mathrm{M}^{-1} \min ^{-1}$ (Fig. 6D, Eq. (3)), these temporary fits are not shown. Afterward, the value of $2000 \mathrm{M}^{-1} \mathrm{~min}^{-1}$ was assigned to $k_{c 1}$ as a fair compromise between all the experiments. The water-related constants were still implemented as the apparent coefficient $k_{w}^{a p p}$, the latter being dependent on the current water concentration. The true constants $k_{w}, k_{w w}$ and $K_{w w}$ were established in Section 4.7 where also $k_{f w}$ was conjectured. Afterward, the solid curves of the final model (Table 1) were generated to demonstrate a satisfactory global fit (Fig. 6C and D).

\subsection{Distribution of alcohols between oil and water phases}

Measurements of Nile Red fluorescence in biodiesel with $1 \mathrm{M}$ alcohol (with or without $2 \mathrm{M}$ water added) indicated transition of alcohols to water phase. The amounts of $\mathrm{MeOH}$ and $\mathrm{EtOH}$ remaining in oil phase were different: $1 / 3$ and $2 / 3$, respectively. This means that the kinetic schemes for $\mathrm{MeOH}$ and $\mathrm{EtOH}$ should be treated somewhat differently. Assumption of a complex-formation between water and alcohol, like the molecular species of CW, CWW, CCWW etc., was abandoned as leading to an explosive branching of the model. Yet, the difference in $\mathrm{MeOH}$ and $\mathrm{EtOH}$ properties was interpreted via water-related constants, assuming that redistribution of $\mathrm{MeOH}$ and EtOH affects association and activity of the aggregated water, e.g. $\mathrm{W}+\mathrm{W} \leftrightarrow \mathrm{WW}+\mathrm{C} \leftrightarrow \mathrm{CWW}$. For the sake of simplicity, C was not incorporated into WW in the scheme, but the characteristics of WW were assumed to be different for $\mathrm{MeOH}$ and EtOH.

\subsection{Equilibrium analysis}

The equilibrium concentrations of $f, b, c$, and $\sum w$ were calculated from the data in Figs. 4A, C, 5A, C and 6A, B and the two other experiments analogous to those in Fig. $6 \mathrm{~A}$ and $\mathrm{B}$, but performed at $0.75 \mathrm{M}, 0.25 \mathrm{M} \mathrm{MeOH}$ (not shown). The concentration changes $\Delta f$ determined the total material balance $-\Delta f=-\Delta c=+\Delta b=+\Delta \sum w$, which made possible calculation of all equilibrium concentrations based on $-\Delta f$ record, e.g. $f_{e q}=f_{0}-\Delta f$. Finally, the apparent con- 

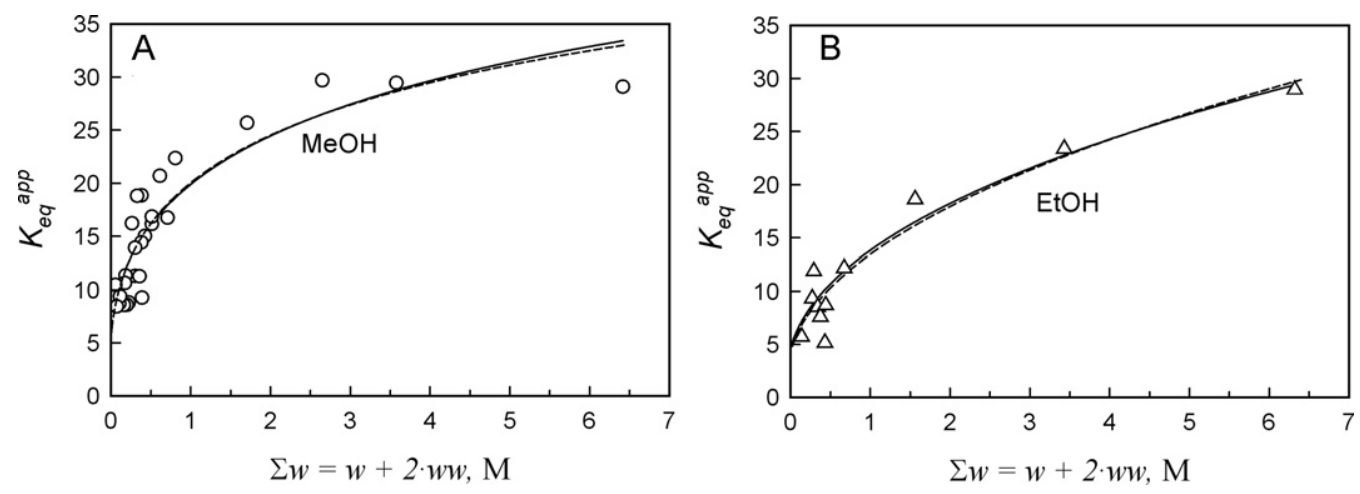

Fig. 7. The apparent equilibrium constant of the reaction $\mathrm{F}+\mathrm{C} \leftrightarrow \mathrm{B}+\sum \mathrm{W}$ plotted as a function of equilibrium $\sum w$. The data for $(\mathrm{A}) \mathrm{MeOH}$ and (B) EtOH reactions. Dashed lines indicate the best fits, and the solid lines show the approximations reached by the final model (Table 1 ).

stant $K_{e q}^{a p p}=\left(b_{e q} \cdot \Sigma w_{e q}\right) /\left(f_{e q} \cdot c_{e q}\right)$ was calculated and plotted as a function of $\sum w_{e q}$ (Fig. 7A and B).

The apparent equilibrium ratio depends on equilibrium $\sum w$ according to the below function (see also Appendix (C1)-(D2)):

$K_{e q}^{a p p}=\frac{b \cdot \Sigma w}{c \cdot f}=\frac{k_{c} \cdot\left(k_{f}+k_{f w} \cdot w\right)}{k_{b} \cdot\left(k_{w}(w / \Sigma w)+k_{w w}(w w / \Sigma w)\right)} ;$

$w=F_{\left(\Sigma w, K_{w w}\right)} ; \quad w w=F_{\left(\Sigma w, K_{w w}\right)}$

where $w$ and $w w$ were calculated from $\sum w$, see Appendix C. The above equation contains three known parameters $\left(k_{b}, k_{c}, k_{f}\right)$ and four unknown water-related constants $k_{w}, k_{w w}, k_{f w}$ and $K_{w w}$ (see the scheme in Fig. 1C). One of the constants $\left(k_{f w}\right)$ describes a process $\mathrm{E}+\mathrm{F}+\mathrm{W} \rightarrow \mathrm{EX}+\mathrm{WW}$. Velocity of this conversion is expected to be very low, because probability of formation of EX complex under simultaneous interaction of the enzyme with fatty acid and water is not high. We assigned $k_{f w}=10 \mathrm{M}^{-1} \mathrm{~min}^{-1}$, though any $k_{f w} \leq 50 \mathrm{M}^{-1} \mathrm{~min}^{-1}$ can be used with a very little effect on the model.

After assignment of $k_{b}, k_{c}, k_{f}$ and $k_{f w}$, the unconstrained optimization of $k_{w}, k_{w w}$ and $K_{w w}$ was performed separately for $\mathrm{MeOH}$ (Fig. 7A) and EtOH (Fig. 7B), dashed lines. Different behavior of water in $\mathrm{MeOH}$ and $\mathrm{EtOH}$ reactions was assumed because of different solubility of alcohols in biodiesel when water was also present, see Section 4.6. The optimal values of the water-related constants (Fig. 7) were afterward subjected to adjustments. Thus, the value of $k_{w}$ was assumed to be the same in both $\mathrm{MeOH}$ and EtOH reactions, because no alcohol redistribution occurs at low water content. Two other coefficients $k_{w w}$ and $K_{w w}$ were treated as being affected by $\mathrm{MeOH}$ and $\mathrm{EtOH}$. The approximations based on the final model (Table 1) are shown in Fig. 7A and B as solid lines.

\subsection{Temperature dependence}

Comparison of the reaction $\mathrm{F}+\mathrm{C} \rightarrow \mathrm{B}+\mathrm{W}$ performed at $30^{\circ} \mathrm{C}$ and $40^{\circ} \mathrm{C}$ pointed to 1.55 acceleration of the velocity for both alcohols (not shown).

\subsection{Modeling of the reaction}

In the previous sections we have obtained the relevant parameters of the model, which are summarized in Table 1 . These coefficients were used to explore behavior of the system under different conditions. Among the addressed questions were (i) possibility to reduce the contents of fatty acids in $96 \%$ biodiesel from $4 \%$ to $0.2 \% \mathrm{~F}$ by means of the enzymatic conversion; and (ii) selection of the optimal scenario for such conversion.

To answer the first question, the equilibrium equation (Eq. (4)) was solved in terms of $f_{e q}$ to produce a dependency of free fatty acids on the equilibrium values of $c_{e q}$ and $\sum w_{e q}$. Concentration of $b_{e q}$ was eliminated via its material balance $b_{e q}=3-f_{e q}$ or $b_{e q}=2.84-f_{e q}(\mathrm{M})$ for $\mathrm{MeOH}$ and $\mathrm{EtOH}$ reactions, respectively. The below expression was reached (example for $\mathrm{MeOH}$ ):

$f_{e q}=\frac{3 \cdot \Sigma w_{e q}}{K_{e q}^{a p p} \cdot c_{e q}+\Sigma w_{e q}} ; \quad K_{e q}^{a p p}=F_{\left(\Sigma w_{e q}, K_{w w}\right)}$

where $K_{e q}^{a p p}$ is a function of the total water (Eq. (4)). Then, Eq. (5) was used to simulate the theoretical curves, (Fig. 8A and C). Relations between the molar concentrations and concentrations in percent are as follows: $0.1 \mathrm{M} \mathrm{H}_{2} \mathrm{O}$ corresponds to $2000 \mathrm{ppm}(\mathrm{m} / \mathrm{m}) ; 0.1 \mathrm{M}$ $\mathrm{F}$ corresponds to $3 \%(\mathrm{~m} / \mathrm{m})$; complete conversion of $0.1 \mathrm{M} \mathrm{F}$ gives $2000 \mathrm{ppm}$ of water; $1 \mathrm{M}$ alcohol is equivalent to $4 \%(\mathrm{v} / \mathrm{v})$ of $\mathrm{MeOH}$ and $5.8 \%(\mathrm{v} / \mathrm{v})$ of EtOH.

The results in Fig. $8 \mathrm{~A}$ and $\mathrm{C}$ clearly demonstrated that a mixture of $96 \% \mathrm{~B}$ and $4 \% \mathrm{~F}$ (with $100-200 \mathrm{ppm}$ of water) cannot be converted to $99.8 \% \mathrm{~B}+0.2 \% \mathrm{~F}$ in course of a one-step enzymatic reaction, because the shift of equilibrium will require presence of $5 \mathrm{M}$ $\mathrm{MeOH}(20 \%)$ or $8 \mathrm{M} \mathrm{EtOH} \mathrm{(46 \% ).} \mathrm{Thus} \mathrm{is} \mathrm{far} \mathrm{above} \mathrm{the} \mathrm{safe} \mathrm{levels} \mathrm{for}$ Novozym 435 estimated as $\mathrm{MeOH} \leq 2 \mathrm{M}$ and $\mathrm{EtOH} \leq 3 \mathrm{M}$. A singlestep conversion of $\mathrm{F}$ from $1 \%$ to $0.2 \%$ can be, however, reached, because $6 \% \mathrm{MeOH}$ and $13 \% \mathrm{EtOH}$ are required.

$\mathrm{F}$ at concentrations above $1 \%$ should be processed in several steps, where both alcohol and water are evaporated in a separated from the enzyme unit. The industrial drying equipment provides $\approx 100 \mathrm{ppm}$ of residual water in $30-60 \mathrm{~min}$. Under these assumptions, the conversion of $96 \% \mathrm{~B}+4 \% \mathrm{~F}$ might be achieved in three steps as shown in Fig. 8B (MeOH) and Fig. 8D (EtOH). The presented simulations corresponded to $5 \%(\mathrm{~m} / \mathrm{v})$ Novozym 435 at $35^{\circ} \mathrm{C}$. The stages of conversion in Fig. $8 \mathrm{~B}$ should be interpreted as follows: ( $0 \mathrm{~min}) 4 \% \mathrm{MeOH}$ is added to the mixture and the reaction proceeds; ( $30 \mathrm{~min}$ ) the mixture is transferred to a drying unit and both water and $\mathrm{MeOH}$ are evaporated $(100 \mathrm{ppm}$ of residual water is reached, where kinetics is not specified); $(60 \mathrm{~min})$ the mixture is transferred to the reaction unit and $4 \% \mathrm{MeOH}$ is added; (90 min) next drying is performed; $(120 \mathrm{~min})$ final reaction is started with $3 \% \mathrm{MeOH}$. The process with EtOH proceeds in a similar way except for higher concentrations of alcohol required at each step.

The data from Table 1 can be used for modeling of other scenarios, e.g. processing of pure $\mathrm{F}$ to $\mathrm{B}$ or reduction of $\mathrm{F}$ contents in oils to the level acceptable for alkaline conversion. In the later case, $\mathrm{T}$ (as the main component of oil) can be treated as a "neutral" substance, because reactivity of T with Novozym 435 is much slower than that of $\mathrm{F}$ according to our preliminary data. It also appears that conversion of $\mathrm{F}$ in $\mathrm{T}$-solution is twice as slow as in B-solution, which is presently interpreted as formation of unproductive complexes between $\mathrm{E}$ and $\mathrm{T}$. 

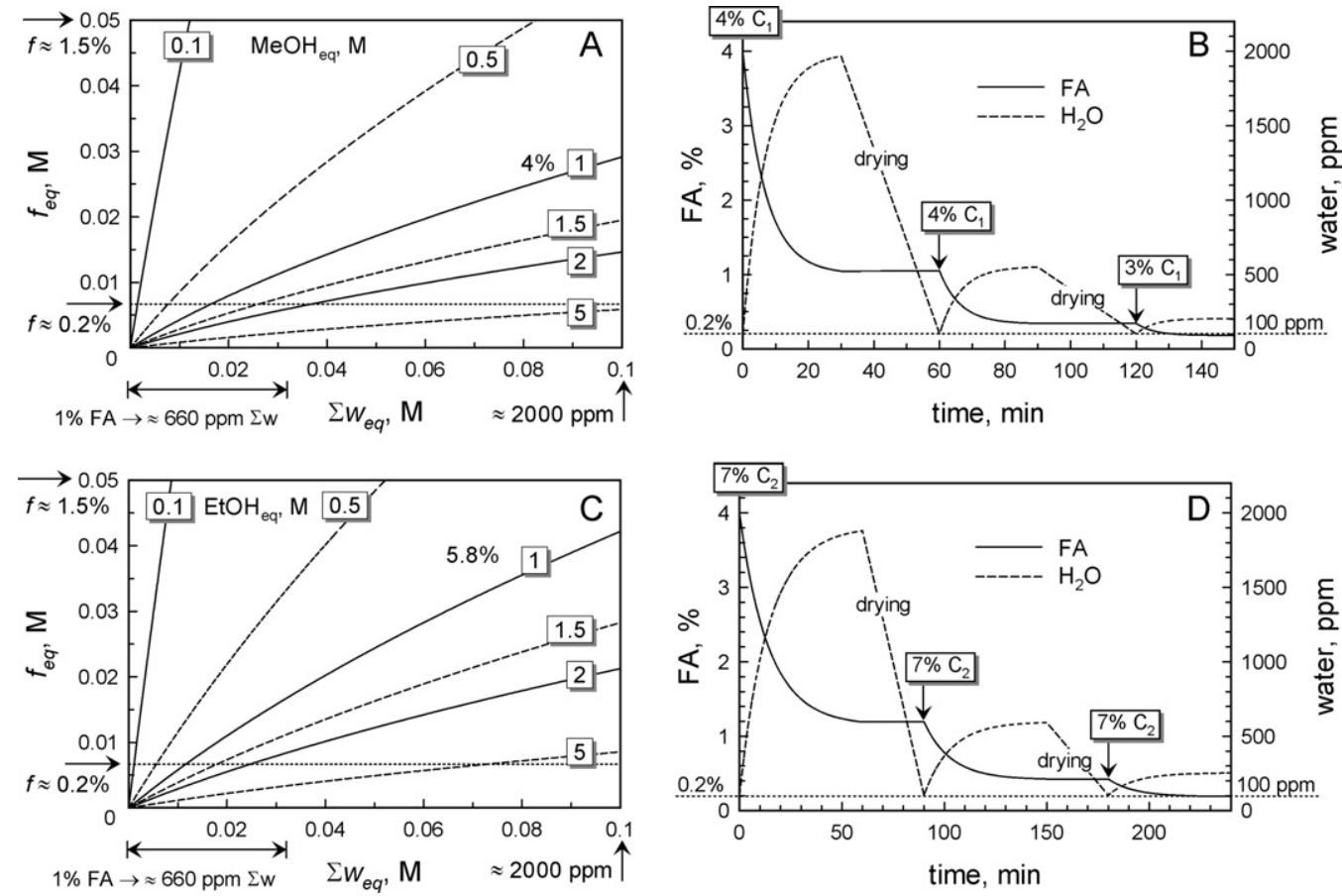

Fig. 8. Computer simulations of the reaction $\mathrm{F}+\mathrm{C} \leftrightarrow \mathrm{B}+\sum \mathrm{W}$. (A) Dependence of the equilibrium fatty acid concentration $\left(f_{\text {eq }}\right)$ on the equilibrium water concentration $\left(\sum w_{e q}\right)$ in the presence of different $\mathrm{MeOH}$ concentrations. The targeted level of $\mathrm{F}(0.2 \%)$ is shown by dotted line. (B) Stepwise conversion of $\mathrm{F}$ dissolved in biodiesel in the presence of $\mathrm{MeOH}\left(c_{1}, \% \mathrm{v} / \mathrm{v}\right)$, Novozym $435(5 \%, \mathrm{~m} / \mathrm{v})$ at $35^{\circ} \mathrm{C}$. Levels of $\mathrm{F}$ and $\mathrm{H}_{2} \mathrm{O}$ are depicted by solid and dashed lines, respectively. The reaction steps are alternated with water drying (drying kinetics is not specified, final water of $100 \mathrm{ppm}$ ). (C) and (D) EtOH used instead of MeOH, descriptions as in panels A and B, respectively.

\section{Discussion}

\subsection{The analyzed scheme}

The current work investigated the enzymatic esterification of fatty acids by $\mathrm{MeOH}$ and $\mathrm{EtOH}$ in the reaction $\mathrm{F}+\mathrm{C} \leftrightarrow \mathrm{B}+\sum \mathrm{W}$ (see Fig. 1C for a detailed description). This reaction is an important part of the global scheme related to production of biodiesel from vegetable oils [1-6]. We have already discussed in the Introduction that the global kinetic scheme is too complex to be solved in the fullcomponent mixture. Our strategy was based on the investigation of one individual reaction with a limited number of ligands, where biodiesel had a dual role as both the medium and the product. Such approach allows a gradual assembly of the whole model, where novel elements will be introduced at the next stage of our work.

Conversion of $\mathrm{F}$ to $\mathrm{B}$ presents a very convenient starting point of investigation, because this segment of the process does not produce the cross-reacting ligands (T, D, M), and complexity of the scheme can be kept at a reasonable level. The rate constants for alcohols and biodiesel determined under F-reaction could be used in all models of the future analysis. Examination of F-conversion was important also as a separate study, because decrease of $\mathrm{F}$ below the specification level of $0.25 \%(\mathrm{~m} / \mathrm{m})$ by means of the enzymatic catalysis appeared to be the most challenging task according to our previous experiments [11]. The global strategy of enzymatic B production might consider the initial conversion of oil to biodiesel of $90-96 \%$ purity [11] followed by "polishing" cycle(s), where the remaining contaminations are converted to $\mathrm{B}$. In this publication we examine the "polishing" process with particular focus on $\mathrm{F}$.

The scheme of F-conversion was based on a shortened presentation of the ping-pong mechanism, where the original four-step process (Fig. 1A) was condensed to a two-step scheme (Fig. 1B), see Appendix (A1) and (A2). The model also considered reversible inhibition of the enzyme by alcohol and aggregation of water forming a separate layer WW with low chemical activity.

\subsection{Monitoring of the reaction}

Monitoring of the concentration changes was based on a novel approach, where the fluorescent signal from Nile Red (Fig. 2) was correlated with the reactant of interest (e.g. F) via parallel records of fluorescence and concentrations (Fig. 3). The chosen method made possible prognosis of the fluorescence for various reaction conditions even at a few calibrations shown in Fig. 3. Additionally, dispersion of the fluorescent signal was lower than that of TLC, which increased reliability of the data.

Presence of multiple calibration curves for exactly the same reaction seems to be strange at a first look. Yet, this fact can be explained by effects of phase separation. Water (either added or generated under the reaction) causes redistribution of alcohols between oil and water phases. In such case, the amount of alcohol in the oil phase depends on both the chemical stoichiometry $(\mathrm{F}+\mathrm{C} \leftrightarrow \mathrm{B}+\mathrm{W})$ and the equilibrium with water (e.g. $\mathrm{C}+\mathrm{W} \leftrightarrow \mathrm{CW})$. Alcohol in the hydrophobic phase affects the fluorescence of Nile Red, making the calibration dependent on the redistribution effects. Additionally, enzyme particles appear to adsorb some reactants on their surface. This means that (i) one cannot use the artificial mixtures to prepare a calibration, and (ii) different enzymes might require separate calibrations.

\subsection{Stepwise solution of the kinetic scheme}

Analysis of data had been done in steps. In the beginning, the concentrations were recorded over time (e.g. $\Delta f$ vs $t$ in Fig. 4A and $C$ ), and the charts were fitted by exponential functions. Good exponential approximations indicated that the enzyme is indeed unsaturated, and the suggested simplification of the ping-pong mechanism (Fig. 1B) is valid. The initial velocities were calculated, normalized to the enzyme concentration $\left(v / e_{0}\right)$ and plotted as functions of the corresponding substrate concentration (e.g. Fig. 4B and C). 
The meticulously planned combinations of substrates were used to dissemble the reaction scheme in Fig. 1C into several segments, where only a few constants were evaluated per time. For example, analysis of the backward reaction $\mathrm{B}+\sum \mathrm{W} \rightarrow \ldots$ (Fig. 4) helped to establish the values of $k_{b}$ for $\mathrm{MeOH}$ and $\mathrm{EtOH}$, as well as make a rough evaluation of $k_{w}$. The other rate constants were ignored at this stage.

Then, experiments with the forward reaction were conducted using two different schemes of substrate supply: (i) variable alcohol concentration at a constant F; or (ii) variable F on the background of a constant alcohol. The velocity dependencies on either $c$ or $f$ are shown in Figs. 5B, D and 6C, D. All these charts had $k_{f}$ as a common parameter, and a comparative examination revealed its value (Table 1). The curves in Fig. 5B and D assisted in finding of $k_{c}$ and $K_{i c}$, which were additional verified for $\mathrm{MeOH}$ in Fig. $6 \mathrm{C}$ and D.

When the above stage was accomplished, the water-related constants became the subject of investigation. Determination of the true water constants was done in an equilibrium assay (Fig. 7) where the ratio $\left(b \cdot \sum w\right) /(f \cdot c)$ was plotted as a function of $\sum w$, see Appendix (D1) and (D2) and Eq. (4). Despite the same water in all experiments, we treated the water constants as being different for $\mathrm{MeOH}$ and $\mathrm{EtOH}$. This was done to compensate redistribution of alcohols between oil and water phases, which was not identical for $\mathrm{MeOH}$ and EtOH. Such compensation could have been done either by introducing water-alcohol complexes (CW, CWW, etc.) or assuming different association and activity properties of water droplets WW in the presence of $\mathrm{MeOH}$ or EtOH. The latter approach was by far less troublesome, and it was used with satisfactory results. Absence of any kinetic manifestation of alcohol redistribution in the alcohol-related rate constants might imply, that $\mathrm{MeOH}$ and EtOH occupy the surface of water droplets and remain exposed, whereas water itself becomes hidden in the bulk. The results of performed analysis are summarized in Fig. 7 and Table 1.

\subsection{Modeling of F conversion}

The detailed characterization of the F conversion was used to examine various scenarios of this reaction. It has previously been found that a single-step conversion is not sufficient to make a biodiesel product conforming to the specifications [1-3]. For example, introduction of water to the reaction mixture (necessary for high activity of the enzyme Lipozyme TL HC) caused accumulation of $F$ in B [11]. Therefore, a "polishing" step seemed to be necessary, where biodiesel with a few percents of $F$ should be subjected to additional treatment with Novozym 435 . The final contents of $F$ was chosen as $0.2 \%$ as being well below the specification of $0.25 \%$. Numerous variants of the process were examined by computer modeling. The equilibrium curves are shown in Fig. 8A and B, and they indicate that conversion of $\mathrm{F}$ to $0.2 \%$ in a single "polishing" step is unrealistic if the initial contents of $F$ exceeds $1 \%$. The shift of equilibrium would require a high alcohol concentration, resulting in an scenarios are possible if using the data from Table 1 and a suitable computer program (e.g. COPASI [14]).

\section{Conclusions}

Enzymatic conversion of fatty acids to biodiesel was examined and quantified in terms of the relevant kinetic constants. The effect of $\mathrm{MeOH}$ and $\mathrm{EtOH}$ on the overall equilibrium and the enzymatic activity was examined. Separation of water into an individual phase was approximated by a simple association scheme. A functional computer model was designed, and a number of "virtual experiments" allowed a fast optimization of the process. The current model is a part of a full biodiesel scheme being in preparation.

\section{Acknowledgment}

This work was supported by a grant from the Danish National Advanced Technology Foundation.

\section{Appendix A. Simplification of the ping-pong mechanism}

The "classical" velocity expression for the ping-pong mechanism (Fig. 1A) in the absence of any products can be presented as follows:

$$
\begin{aligned}
& \frac{v}{e_{0}}=\frac{V_{+}}{1+K_{m 1} / s_{1}+K_{m 2} / s_{2}} ; \quad V_{+}=\frac{k_{p 1} \cdot k_{p 2}}{k_{p 1}+k_{p 2}} ; \quad K_{m 1}=\frac{K_{s 1} \cdot k_{p 2}}{k_{p 1}+k_{p 2}} ; \\
& K_{m 2}=\frac{K_{s 2} \cdot k_{p 1}}{k_{p 1}+k_{p 2}}
\end{aligned}
$$

This equation becomes simplified if the concentrations of substrates are much lower than the corresponding Michaelis constants:

$\frac{v}{e_{0}} \approx \frac{k_{s 1} \cdot k_{s 2} \cdot s_{1} \cdot s_{2}}{k_{s 1} \cdot s_{1}+k_{s 2} \cdot s_{2}} ; \quad k_{s 1} \approx \frac{k_{p 1}}{1.3 \cdot K_{s 1}} ; \quad k_{s 2} \approx \frac{k_{p 2}}{1.3 \cdot K_{s 2}}$

This expression corresponds to the scheme shown in Fig. 1B. It should be noted that introduction of the correction coefficients (e.g. 1.3) to $k_{s 1}$ and $k_{s 2}$ expressions extends applicability of the velocity Eq. (A2) from a very low saturation level to $v \leq 0.4 \cdot V_{\max }$ as discussed elsewhere [15]. The elementary two-step mechanism in Fig. 1B was used to draw the full reaction scheme in Fig. 1C.

\section{Appendix B. Global model}

The King-Altman master pattern of the considered steady-state reaction is shown in Fig. 1C. It is supplemented by two equilibriums: (i) an unproductive binding of alcohol to the free enzyme and (ii) aggregation of water. The below general equation was derived:

$$
\frac{v}{e_{0}}=\frac{N_{+}-N_{-}}{D}=\frac{k_{f}^{*} \cdot f \cdot k_{c} \cdot c+k_{f w}^{*} \cdot f \cdot w \cdot k_{c} \cdot c-k_{b}^{*} \cdot b \cdot k_{w} \cdot w-k_{b}^{*} \cdot b \cdot k_{w w} \cdot w w}{k_{f}^{*} \cdot f+k_{c} \cdot c+k_{b}^{*} \cdot b+k_{w} \cdot w+k_{f w}^{*} \cdot f \cdot w+k_{w w} \cdot w w}
$$

irreversible damage to the enzyme. The "safe" limits for Novozym 435 were estimated as $1.5 \mathrm{M} \mathrm{MeOH}(6 \%)$ and $2 \mathrm{M} \mathrm{EtOH} \mathrm{(12 \% ).}$

The decrease of $\mathrm{F}$ from $4 \%$ to $0.2 \%$ could be done in three steps instead of one; by alternating the reaction with water drying (final level of water $\approx 100 \mathrm{ppm}$ ). The two convenient scenarios for $\mathrm{MeOH}$ and EtOH were simulated in Fig. $8 \mathrm{C}$ and D with the overall reaction times of $150 \mathrm{~min}$ and $240 \mathrm{~min}$, respectively. The scheme with a simultaneous evaporation of water and alcohol is also feasible but requires a continuous supply of alcohol to maintain high velocity of forward reaction (not shown). Simulations of numerous other where concentrations of the two water forms $w$ and $w w$ are functions of the total water concentration $\sum w$ (see below Appendix C). Simultaneous presence of substrates and products means that the total velocity $(v=d b / d t)$ is expressed as $v=v_{\text {forward }}-v_{\text {backward }}$, and its value might become negative. The "star" parameters $\left(k_{x}^{*}\right)$ in Eq. (B1) are equal to the below expression $\left(f_{e}\right.$ standing for the fraction of $\mathrm{E})$ :

$k_{x}^{*}=k_{x} \cdot f_{e}=\frac{k_{x}}{1+c / K_{i c}}$ 


\section{Appendix C. Water equilibrium}

Association of water can be described by the below equilibrium equation and the material balance.

$K_{w w}=\frac{w^{2}}{w w} ; \quad \Sigma w=w+2 \cdot w w=w+2 \cdot \frac{w^{2}}{K_{w w}}$

Solution of the quadratic equation provides the expressions for both $w$ and $w w$ as functions of $\sum w$ :

$w=\frac{-1+\sqrt{1+8 \cdot \Sigma w / K_{w w}}}{4 / K_{w w}} ; \quad w w=\frac{1}{2} \cdot(\Sigma w-w)$

\section{Appendix D. The apparent reaction equilibrium}

The full reaction scheme in Fig. 1C describes two isolated equilibriums for W and WW molecular species (both dependent on total water). The equilibrium requires $N_{+}-N_{-}=0$ in Eq. (A1). This leads to the below transformations:

$$
\begin{aligned}
N_{+}-N_{-}= & k_{f}^{*} \cdot f \cdot k_{c} \cdot c+k_{f w}^{*} \cdot f \cdot w \cdot k_{c} \cdot c \\
& -k_{b}^{*} \cdot b \cdot k_{w} \cdot w-k_{b}^{*} \cdot b \cdot k_{w w} \cdot w w=0
\end{aligned}
$$

$k_{c} \cdot\left(k_{f}+k_{f w} \cdot w\right) \cdot f \cdot c=k_{b} \cdot\left(k_{w} \cdot \frac{w}{\Sigma w}+k_{w w} \cdot \frac{w w}{\Sigma w}\right) \cdot b \cdot \Sigma w$

The equilibrium concentrations of $f, c, b, \sum w$ should be regrouped on one side and all the rate constants (as well as water species $w$ and $w w$ ) on another one leading to Eq. (4) presented in Section 4.7.

\section{References}

[1] P.M. Nielsen, J. Brask1, L. Fjerbaek, Enzymatic biodiesel production: technical and economical considerations, Eur. J. Lipid Sci. Technol. 110 (2008) 692-700.
[2] N. Nazir, N. Ramli, D. Mangunwidjaja, E. Hambali, D. Setyaningsih, S. Yuliani, M.A. Yarmo, J. Salimon, Extraction, transesterification and process control in biodiesel production from Jatropha curcas, Eur. J. Lipid Sci. Technol. 111 (2009) 1185-1200.

[3] A. Robles-Medina, P.A. González-Moreno, L. Esteban-Cerdán, E. Molina-Grima, Biocatalysis: towards ever greener biodiesel production, Biotechnol. Adv. 27 (2009) 398-408.

[4] T. Tan, J. Lu, K. Nie, L. Deng, F Wang, Biodiesel production with immobilized lipase: a review, Biotechnol. Adv. 27 (2010) 623-628.

[5] G. Knothe, Biodiesel and renewable diesel: a comparison, Prog. Energy Combust. 36 (2010) 364-373.

[6] M.Y. Koh, T.I.M. Ghazi, A review of biodiesel production from Jatropha curcas L. oil, Renew. Sust. Energy Rev. 15 (2011) 2240-2251.

[7] C.-J. Shieh, H.-F. Liao, C.-C. Lee, Optimization of lipase-catalyzed biodiesel by response surface methodology, Bioresour. Technol. 88 (2003) 103-106.

[8] S.F.A. Halim, A.H. Kamaruddin, W.J.N. Fernando, Continuous biosynthesis of biodiesel from waste cooking palm oil in a packed bed reactor: optimization using response surface methodology (RSM) and mass transfer studies, Bioresour. Technol. 100 (2009) 710-716.

[9] B. Cheirsilpa, A. H-Kittikuna, S. Limkatanyub, Impact of transesterification mechanisms on the kinetic modeling of biodiesel production by immobilized lipase, Biochem. Eng. J. 42 (2008) 261-269.

[10] D.A. Mitchell, F. Carrière, N. Krieger, An analytical method for determining relative specificities for sequential reactions catalyzed by the same enzyme: general formulation, Biochim. Biophys. Acta 1784 (2008) 705-715.

[11] S.N. Fedosov, J. Brask, X. Xu, Analysis of biodiesel conversion using thin layer chromatography and nonlinear calibration curves, J. Chromatogr. A 1218 (2011) 2785-2792.

[12] R.P. Haugland, Handbook of Fluorescent Probes and Research Chemicals, sixth ed., Molecuclar Probes Inc., Eugene, 1996.

[13] P.J.G. Coutinho, Photophysics and biophysical applications of benzo[a]phenoxazine type fluorophores, in: C.D. Geddes (Ed.), Reviews in Fluorescence 2007, Springer Science, Business Media, LLC, New York, 2009, pp. 335-362.

[14] S. Hoops, S. Sahle, R. Gauges, C. Lee, J. Pahle, N. Simus, M. Singhal, L. Xu, P. Mendes, U. Kummer, COPASI - a COmplex PAthway SImulator, Bioinformatics 22 (2006) 3067-3074.

[15] S.N. Fedosov, Metabolic signs of vitamin B12 deficiency in humans: computational model and its implications for diagnostics, Metab. Clin. Exp. 59 (2010) 1124-1138. 